\title{
Low-Frequency Climate Modes and Antarctic Sea Ice Variations, 1982-2013
}

\author{
D. CERRONE \\ Science and Technology Department (DiST), University of Naples Parthenope, Naples, Italy \\ G. FUSCO \\ Science and Technology Department (DiST), University of Naples Parthenope, Naples, and Consorzio Nazionale \\ Interuniversitario per le Scienze del Mare (CoNISMa), Rome, Italy
}

(Manuscript received 21 March 2017, in final form 11 September 2017)

\begin{abstract}
The NCEP-NCAR composite dataset (comprising sea level pressure, 500-hPa geopotential height, 500-hPa temperature, and meridional wind stress at $10 \mathrm{~m}$ above the surface) is used for compiling a set of climate indices describing the most important physical modes of variability in the Southern Hemisphere (SH): the southern annular mode (SAM), semiannual oscillation (SAO), Pacific-South American (PSA), and quasistationary zonal wavenumber 3 (ZW3) patterns. Compelling evidence indicates that the large increase in the SH sea ice, recorded over recent years, arises from the impact of climate modes and their long-term trends. The examination of variability ranging from seasonal to interdecadal scales, and of trends within the climate patterns and total Antarctic sea ice concentration (SIC) for the 32-yr period (1982-2013), is the key focus of this paper. The results herein indicate that a progressive cooling has affected the year-to-year climate of the sub-Antarctic since the 1990s. This feature is found in association with increased positive SAM and SAO phases detected in terms of upward annual and seasonal trends (in autumn and summer) and upward decadal trends. In addition, the SIC shows upward annual, spring, and summer trends, indicating the insulation of Antarctica from the warmer flows in the midlatitudes. This picture of variations is also found to be consistent with the upward trends detected for the PSA and ZW3 patterns on the annual scale and during the last two decades. Evidence of a more frequent occurrence of the PSA-ZW3 combination could explain, in part, the significant increase of the regional and total Antarctic sea ice coverages.
\end{abstract}

\section{Introduction}

In this paper, the low-frequency variability of four large-scale modes of Southern Hemisphere ( $\mathrm{SH})$ climate will be examined. These modes are 1) the southern annular mode (SAM), 2) the semiannual oscillation (SAO), 3) the Pacific-South American mode (PSA), and 4) zonal wavenumber 3 (ZW3). Theoretical and observational considerations suggest that these climate patterns modulate variations affecting the subAntarctic sea ice, occurring on regional to larger spatial scales, and on a wide range of time scales, spanning from daily to interdecadal (Yuan and Li 2008, hereinafter YL08; Holland 2014; Kohyama and Hartmann 2016; Cerrone et al. 2017a). To ascertain and better comprise the already known relationships between these patterns and the sea ice, parallel analyses will be

Corresponding author: D. Cerrone, dario.cerrone@uniparthenope.it also conducted on the Antarctic sea ice concentration (SIC) data series. Here, the investigations will be focused on the recent trends and significant variations shown by total Antarctic SIC and climate modes on seasonal, annual, decadal, and interdecadal time scales over the 32-yr period of monthly mean data spanning from January 1982 to December 2013. Furthermore, the main relationships among these variances will also be examined. Before discussing analysis results, we introduce the reader to the four climate patterns investigated.

\section{a. $S A M$}

The leading extratropical circulation pattern of SH atmospheric variability is the SAM (Jones and Widmann 2004; Gillett et al. 2006; Meneghini et al. 2007). It is a zonally symmetric or annular pattern of atmospheric pressure (see Fig. 1a), with maximum variability over the Antarctic plateau out of phase with that 
(a) SLP Regression Pattern Upon SAMl

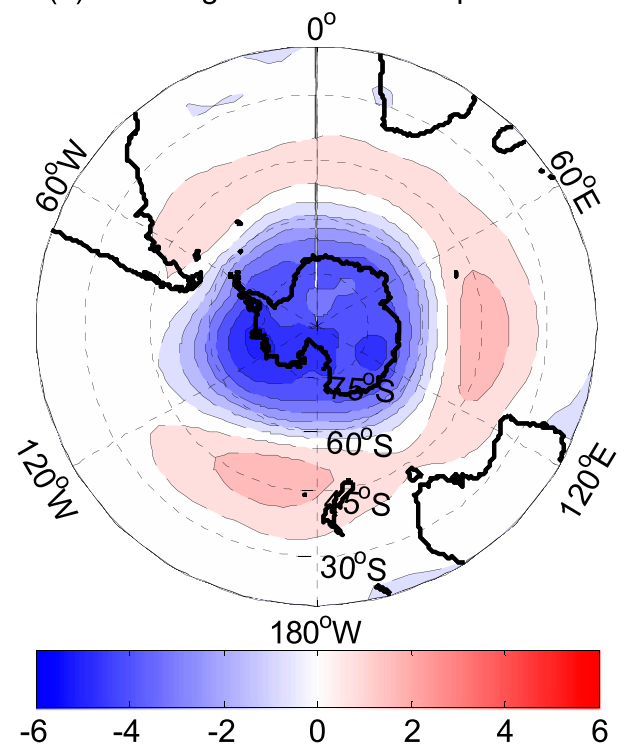

(c) Z500 Regression Pattern Upon PSA index

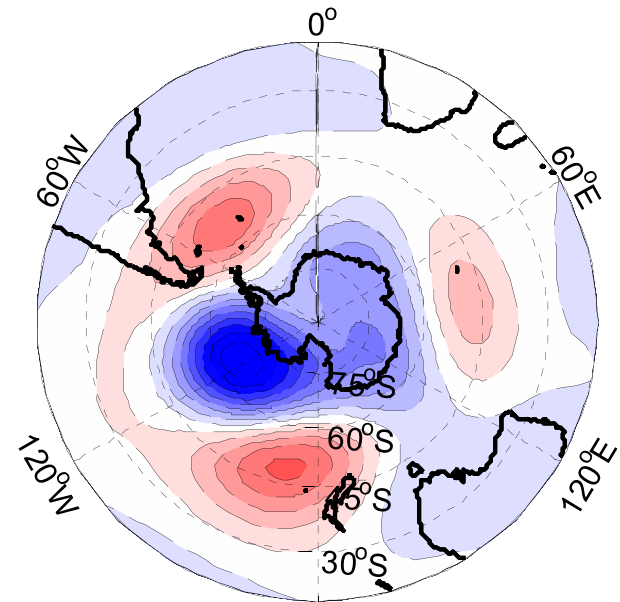

$180^{\circ} \mathrm{W}$

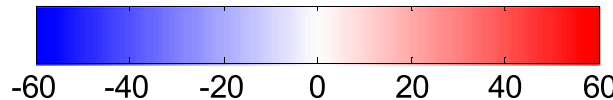

(b) T500 Regression Pattern Upon SAO index

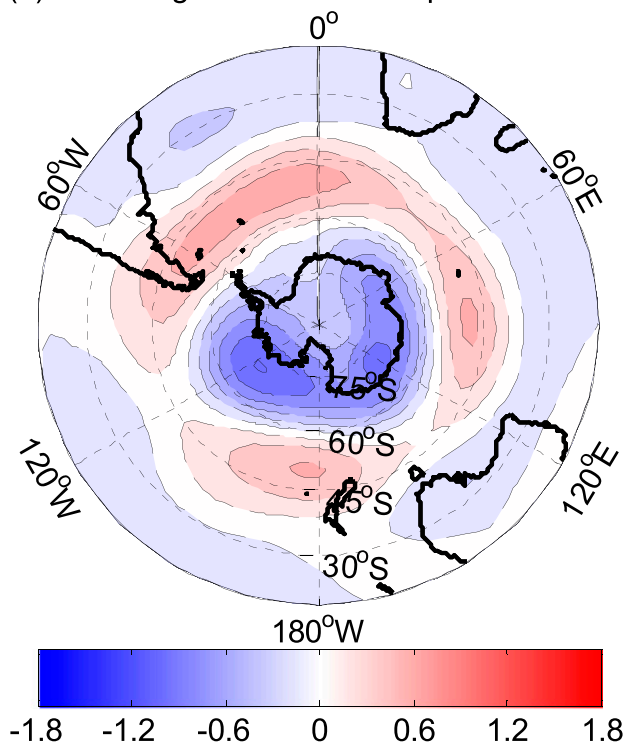

(d) MWS Regression Pattern Upon ZW3 index

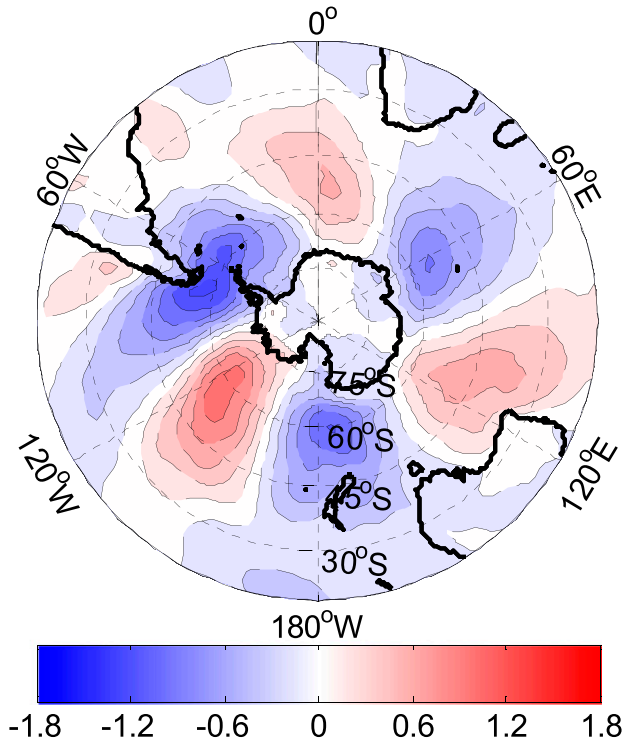

FIG. 1. Spatial pattern generated by regressing the unnormalized and unfiltered (a) SLP anomalies onto the SAMI, (b) T500 anomalies onto the SAO index, (c) Z500 anomalies onto the PSA index, and (d) MWS anomalies onto the ZW3 index. The climate indices are detrended and standardized before the regression. Each map extends from $20^{\circ}$ to $90^{\circ} \mathrm{S}$ for the 32-yr period spanning 1982-2013. White-red (white-blue) colors indicate positive (negative) regression coefficients, with contours at intervals of (a) $0.6 \mathrm{hPa}(1 \mathrm{std} \text { dev of SAMI })^{-1}$, (b) $0.2^{\circ} \mathrm{C}(1 \mathrm{std}$ dev of the SAO index $)^{-1}$, (c) $8 \mathrm{~m}$ (1 std dev of the PSA index $)^{-1}$, and (d) $0.2 \mathrm{~m} \mathrm{~s}^{-1}(1 \mathrm{std} \text { dev of the ZW3 index })^{-1}$.

encircling the Southern Ocean (SO) near $45^{\circ} \mathrm{S}$, extending throughout the troposphere (Rogers and van Loon 1982; Szeredi and Karoly 1987; Yoden et al. 1987; Karoly 1990; Kidson and Sinclair 1995; Gong and Wang 1999, hereinafter GW99; Thompson and Wallace 2000a,b). The SAM shows significant signatures in oceanic and sea ice properties and circulation of the SH (Hall and Visbeck 2002; Holland et al. 2005; Sen Gupta and England 2006) as it reflects the mean westerly winds near $50^{\circ} \mathrm{S}$ (Thompson and Wallace 2000a), the frequency, strength, and track of cold fronts, and extratropical synoptic to mesoscale weather systems (GW99; 
Thompson and Wallace 2000a; Brahmananda Rao et al. 2003; Rashid and Simmonds 2005; Pezza et al. 2008). It also shapes the latitudinal migration of the subtropical upper-level jet and variations in the intensity of the polar jet, affecting, in turn, properties of cyclones such as their origin, minimum/maximum central pressure, and equatorward propagation (Carvalho et al. 2005). The persistence and dominance of the SAM result from the positive feedback between the zonal wind (especially near the region of the eddy-driven midlatitude jet) and fluxes of transient eddy momentum (Karoly 1990; Hartmann and Lo 1998; Lorenz and Hartmann 2001; Codron 2005), this being the leading factor that increases the total variability of zonal winds. The SAM is generally depicted as a yearly tropospheric pattern, but extending upward into the stratosphere during spring (Thompson and Wallace 2000a,b; Polvani et al. 2011). In this season, the stratospheric ozone depletion is consistent with changes observed in the latitudinal position of the midlatitude jet and circulation of $\mathrm{SH}$, which simultaneously accompany the strengthening of the SAM and the cooling of the lower-stratosphere polar cap and of troposphere (Son et al. 2008; Polvani et al. 2011). These thermal effects also result in the poleward shift of the Hadley cell edge (Polvani et al. 2011). The SAM modulates the sea ice coverage such as thinner (thicker) sea ice near the coast and thicker (thinner) sea ice near the edge result by the impact of a positive (negative) SAM phase (Hall and Visbeck 2002). Lefebvre et al. (2004) pointed out that an out-of-phase sea ice response is observed in the Ross and Weddell Seas as a result of SAM oscillations. In addition, YL08 found the influence of SAM on sea ice to be relatively more important in the south Indian Ocean and less significant on the interannual scale.

\section{b. $S A O$}

The SAO is a coupled ocean-atmosphere mode of variability induced by the difference in insolation characterizing the $\mathrm{SH}$ atmospheric variability and climate on seasonal time scale (van Loon 1967). From summer to autumn, the strong decrease in insolation at the top of the $\mathrm{SH}$ atmosphere is accompanied by the expansion and weakening of the circumpolar trough (CPT). On the contrary, from late autumn to spring, the increase in insolation at the top of atmosphere-which extends northward from the equator, becoming stronger in spring - reflects a contracted and strengthened CPT. These variations affect the SAO, whose pattern is strongly conditioned by the amount of spring warming and drying and autumn cooling and moistening (Ackerley and Renwick 2010), which, in turn, affect the climatological location of pressure anomalies over the seas around Antarctica. Van Loon's (1967) analysis identified the largest thermal difference between the middle and high latitudes exploring properties of temperature difference at $500 \mathrm{hPa}$ between $50^{\circ}$ and $65^{\circ} \mathrm{S}$ (see Fig. 1b), thus detecting the semiannual nature of the CPT. More recent analyses (Meehl 1991; Simmonds and Walland 1998) confirmed van Loon's (1967) statements, finding the SAO as the result of ocean-atmosphere coupling processes. Further studies also investigated and detected significant relationships between El NiñoSouthern Oscillation (ENSO) and the SAO (Meehl 1991; Taschetto et al. 2007). The atmospheric convergence linked to the SAO favors the slow sea ice advance in fall/winter and its fast retreat in spring/summer (Enomoto and Ohmura 1990), and it also affects the open water areas (polynyas) within the sea ice pack (Watkins and Simmonds 1999), where large amounts of sea ice are produced (Van Woert 1999; Fusco et al. 2002, 2009; Rusciano et al. 2013).

\section{c. $P S A$}

The ENSO (Simmonds and King 2004) regional-scale teleconnection in the $\mathrm{SH}$, generally known as the PSA pattern (Karoly 1989; Mo and Higgins 1998), is a standing wave train of atmospheric pressure/geopotential height anomalies that extends southeastward through the Amundsen and Bellingshausen Seas, crosses the Antarctic Peninsula, and projects into the southwest Atlantic (see Fig. 1c). This pattern modulates the weather and climate variability over the SO and sub-Antarctic on time scales ranging from daily (Mo and Ghil 1987) to interseasonal (Mo and Higgins 1998), interannual (Kidson 1988a,b), and interdecadal (Garreaud and Battisti 1999). The PSA mode is also consistent with the Rossby wave response to equatorial anomalous heating (Hoskins and Karoly 1981). The mechanisms linking the tropical ENSO component to the effects seen in the SO are discussed in Liu et al. (2002) and Yuan (2004). The PSA pattern is related to the Madden-Julian oscillation, since this latter signal strongly influences the PSA dynamics (Mo and Paegle 2001). The out-of-phase surface temperatures between the Amundsen-Bellingshausen Seas and the Weddell Sea, inserted into the PSA configuration, are generally known as the Antarctic dipole. These associations strongly influence sea ice properties, also generating opposite anomalies in the two sectors (Yuan and Martinson 2001). In a typical El Niño, higher extensions and lower concentrations of the sea ice are observed in the western Weddell Sea, and opposite conditions prevail in the AmundsenBellingshausen sector. During La Niña, the scheme is inverted (Carleton 1988). During El Niño events, blockings in the circulation are more frequently observed in 
association with mesocyclones, katabatic wind events, colder temperatures, and more sea ice in the western Ross Sea (Carleton 1989).

\section{d. $Z W 3$}

The major large-scale asymmetric atmospheric pattern in the SH is the ZW3. It is a barotropic and quasistationary component of the circulation on daily (Wallace and Hsu 1983; Mo and Ghil 1987; Kidson 1988a,b), seasonal (Mo and White 1985, hereinafter MW), and interannual (Mo and van Loon 1984; Karoly 1989) time scales at latitudes $45^{\circ}-55^{\circ} \mathrm{S}$, and it is characterized by three alternating low and high atmospheric pressure/geopotential height centers located in the Indian, Pacific, and Atlantic sectors (for details, see Fig. 1d). A large number of studies focused on the role of the ZW3 in the SH extratropical circulation. Pioneers studies found the ZW3 pattern to be associated with blocking in the SH (van Loon 1956; Trenberth 1980; Trenberth and Mo 1985). More recently, Reason (2000) postulated that the strength of ridges and troughs associated with the ZW3 pattern may be linked to the SH multidecadal variability. Raphael (2001) noticed that the amplitude of the ZW3 is smaller when reduced Antarctic SICs are observed. Through this finding, she pointed out the importance of the ZW3 pattern in inducing meridional transport of warmer/colder air in the sub-Antarctic, thus presenting the potential impact on the SIC. Turner et al. $(2002,2003)$ ascribed the Antarctic warming of the austral summer 2001/02 to a strong ZW3 pattern. Venegas (2003) and Cerrone et al. (2017b) found the ZW3 to be an essential component of the interannual Antarctic Circumpolar Wave signal. Raphael (2004, hereinafter R04) and Raphael (2007) calculated a ZW3 index to examine the long-term variability and the potential influence of the ZW3 pattern on the SH climate, and to investigate its influence on the Antarctic SIC as well as shown by YL08. Recently, Irving and Simmonds (2015) proposed a novel approach to quantify the planetary wave activity using the strength of the hemispheric meridional flow as a proxy for the zonal wave activity.

This paper is laid out as follows. Data sources are described in section 2 . The examined variability indices are presented in section 3 . The spatial patterns and interrelationships of climate modes are described in section 4. The impact from climate patterns on the SIC distribution is investigated in section 5. Trends within the variability indices are discussed in section 6, and the annual cycle of the total Antarctic SIC and climate modes are examined in section 7. Decadal trends in climate patterns and total Antarctic SIC are presented in section 8 , while interdecadal variations in the annual cycle of climate modes are investigated in section 9 . Temporal variations of climate patterns and total Antarctic SIC are examined in section 10; finally a summary and conclusions are presented in section 11.

\section{Data and methods}

The variability of large-scale circulation patterns in the $\mathrm{SH}$ is investigated by making use of reanalysis datasets. The main objective is to detect and quantify significant variations shown by these climate modes during the last three decades. In parallel, properties of the total SIC distribution around Antarctica are investigated to detect the main changes of climate modesea ice relationships on low-frequency time scales.

\section{Gridded datasets}

The datasets we use comprise monthly mean values of sea level pressure (SLP), 500-hPa geopotential height (Z500), 500-hPa temperature (T500), meridional wind stress at $10 \mathrm{~m}$ above the surface (MWS), and surface air temperature at $2 \mathrm{~m}$ above the surface (SAT), provided by the National Centers for Environmental Prediction (NCEP) and National Center for Atmospheric Research (NCAR) reanalysis (Kalnay et al. 1996). Reanalysis products are classified according to how much the variable is influenced by observed and model data. In this framework the SLP, Z500, and T500 fields are classified as reanalysis class A (strongly affected by observed data), while MWS and SAT data are of class B (model has a strong influence on the analysis value). Although a number of new global reanalysis datasets have been released in recent years (Bracegirdle and Marshall 2012), the NCEP-NCAR data are frequently used for Antarctic studies. Nevertheless, this reanalysis is conditioned by few problems and errors as the PAOBs (i.e., pressure "observations"; Kistler et al. 2001) that are estimates of the SLP produced by the Australian Bureau of Meteorology. The PAOBs problem results in relatively large biases affecting the SLP over East Antarctica starting in 1979; only after 1993, when more in situ observations become available (Hines et al. 2000; Marshall 2002), are substantial reductions in biases observed. However, recent studies (Kistler et al. 2001; Yuan 2004; YL08) suggested that the PAOBs problem appears to be significant on synoptic scales but becomes small in monthly mean fields, also having minimal impacts on the climate patterns here investigated.

Monthly means of optimum interpolation (OI) version 2 (Reynolds et al. 2002) SIC and sea surface temperature (SST) data, provided by the National Oceanic and Atmospheric Administration (NOAA), are also used. The OI analysis is produced on a $1^{\circ}$ longitude-latitude 
grid using in situ and satellite SST plus SST simulated by sea ice cover, and the sea ice field shows the approximate monthly average of SIC values stored as the percentage of covered area. Simulated SST corresponds to a value of $-1.8^{\circ} \mathrm{C}$ (i.e., the freezing point of seawater with a salinity of 34 practical salinity units), in grid boxes where the SIC is at least $90 \%$.

The signals presented above cover the 32-yr period spanning from January 1982 to December 2013. To remove the seasonal cycle in the gridded datasets, monthly deviations are calculated by subtracting from each individual monthly average the 32-yr average for that month.

\section{Indices of climate modes and sea ice concentration}

As stated before, four leading circulation climate patterns (SAM, SAO, PSA, and ZW3) are considered in this study. Time series of these climate oscillations are reconstructed based on those used in the literature. Following the definition of the southern annular mode index (SAMI) proposed by Nan and Li (2003), the SLP anomaly is used for describing the SAM pattern variability:

$$
\mathrm{SAMI}=\mathrm{SLP} * 40^{\circ} \mathrm{S}-\mathrm{SLP} * 70^{\circ} \mathrm{S}
$$

where SLP* is the standardized zonal mean SLP anomaly (at $40^{\circ}$ and $70^{\circ} \mathrm{S}$ ). The index is based on the GW99 method, but it differs in that the southernmost latitude is taken as $70^{\circ} \mathrm{S}$ rather than $65^{\circ} \mathrm{S}$ in GW99's definition. Nan and $\mathrm{Li}$ (2003) showed that the negative correlation in the zonal mean SLP anomalies between $40^{\circ}$ and $70^{\circ} \mathrm{S}$ is stronger than between $40^{\circ}$ and $65^{\circ} \mathrm{S}$ and hence more truly captures the nature of the annular mode.

The SAO index is calculated as the difference between the T500 zonal mean at $50^{\circ}$ and $65^{\circ} \mathrm{S}$ :

$$
\text { SAO index }=\mathrm{T} 50050^{\circ} \mathrm{S}-\mathrm{T} 50065^{\circ} \mathrm{S} .
$$

This definition, proposed by van Loon (1967), reflects the magnitude of the meridional thermal gradient between the middle and high latitudes of the SO. In detail, two maxima in the temperature difference are approximately centered on March and September/October, with a stronger temperature difference in autumn than in spring, as highlighted by van Loon (1967) and Meehl (1991). Whereas the SAO shows a dominant twice-yearly cycle in zonal atmospheric pressure/geopotential height, surface temperature and other climate associations for the sub-Antarctic (van Loon 1967), the SAM pattern exists year round (Thompson and Wallace 2000a,b; Thompson et al. 2002). Although the SAM and SAO exhibit two zonally symmetric and highly similar patterns, the atmospheric pressure on Antarctica mostly contributes to the SAM variability, but not necessarily to that of SAO (YL08).

Following YL08, the PSA index is reconstructed composing the time series of monthly Z500 anomalies at three anomalous centers in the southwest Atlantic (H1), in the east of New Zealand (H2), and in the Amundsen Sea $(\mathrm{H} 3)$ :

$$
\begin{aligned}
\text { PSA index }= & 1 / 3\left[\mathrm{H} 1\left(50^{\circ} \mathrm{S}, 45^{\circ} \mathrm{W}\right)+\mathrm{H} 2\left(45^{\circ} \mathrm{S}, 170^{\circ} \mathrm{W}\right)\right. \\
& \left.-\mathrm{H} 3\left(67.5^{\circ} \mathrm{S}, 120^{\circ} \mathrm{W}\right)\right] .
\end{aligned}
$$

A positive PSA index denotes a cold ENSO event, this latter being consistent with an anomalously low SLP in the Amundsen Sea (H3) and positive SLP anomalies east of New Zealand (H2) and in South America and the South Atlantic (H1). Reverse phases for the three centers are identified during a warm ENSO event.

The ZW3 is a zonally barotropic and quasi-stationary pattern of variation in the SH circulation, whose oscillations can be represented by making use of the large number of ZW3 indices presented in the literature. MW proposed a ZW3 index composing the monthly mean SLP anomalies in three fixed locations at $\left(50^{\circ} \mathrm{S}, 95^{\circ} \mathrm{E}\right)$, $\left(58^{\circ} \mathrm{S}, 150^{\circ} \mathrm{W}\right)$, and $\left(38^{\circ} \mathrm{S}, 5^{\circ} \mathrm{W}\right)$. Similarly, R04 suggested a ZW3 index based on Z500 anomalies at $49^{\circ} \mathrm{S}$ and longitudes of $50^{\circ} \mathrm{E}, 166^{\circ} \mathrm{E}$, and $76^{\circ} \mathrm{W}$ (a definition that presents the opposite phase compared to that of $\mathrm{MW}$ ). YL08 presented the leading empirical orthogonal function (EOF) mode in monthly MWS data as the time series of the ZW3 pattern. This definition is consistent with that proposed by R04 in that the longitudes of the three northerly branches coincide with the zonal positions of the ZW3 ridges in Z500 field (van Loon and Jenne 1972; R04). However, the latitudinal locations of the ZW3 centers in YL08's analysis are more southern (near $60^{\circ} \mathrm{S}$, and hence getting close to the sea ice zone) than those adopted by R04, and hence the ZW3 index defined in that way may be expected to have a stronger relationship with sea ice variations.

We adopted the definition of YL08 for the ZW3 index that is the leading EOF mode of monthly MWS, since it provides a good representation of meridional air fluxes affecting the Antarctic sea ice. This leading mode accounts $7 \%$ of the total variance in monthly time series as in YL08's analysis. The character of this EOF is tested through the "rule of thumb" formulated by North et al. (1982), which confirms this mode is not "degenerated." A positive index phase denotes three high pressure centers (HPCs) approximately located in the three fixed 
locations chosen by MW, and three alternating low pressure centers (LPCs). This configuration results in poleward (equatorward) warmer (colder) air fluxes in the western Indian (eastern Indian), western Pacificwestern Ross (eastern Ross-Amundsen), and eastern Bellingshausen-Antarctic Peninsula-western Atlantic (eastern Atlantic) sectors. The opposite is observed during a negative index phase.

Investigations of sea ice properties conventionally require the use of sea ice-covered area (SIA) and sea ice extent (SIE) data. Although a number of satellitederived approaches exist for estimating sea ice thickness (Tamura et al. 2007; Aulicino et al. 2014), these are still under validation or limited to a certain sea ice thickness range, type, and/or region and so are not suitable to be included in this study. While the SIA is defined as the area of each satellite grid cell with at least $15 \%$ ice concentration multiplied by the sea ice fraction in the grid cell (0.15-1.00), the SIE definition is based on "ice-covered" or "not-ice-covered" regions. In detail, each satellite grid cell with at least $15 \%$ ice concentration is considered ice covered, or $100 \%$ ice. As a consequence, the multiplication of the grid cell area for $100 \%$ sea ice returns the SIE metric. In this paper we calculate a time series for the total Antarctic SIC (hereinafter TSIC index) averaging the monthly SIC anomalies over all longitudes of the SH. For this aim, only SIC anomalies (different from zero) localized in grid points where the sea ice alternates with the seawater during the year and anomalies associated with the steady presence of the sea ice throughout the year are averaged. The definition adopted here differs from those presented above for the SIA and SIE metrics because our TSIC index also incorporates satellite grid cells having more than $0 \%$ ice concentration. We argue that the TSIC index better represents the total Antarctic SIC distribution because it takes into account all the sea ice values, also providing a more complete vision of variations within the sea ice pack that occurred in the last three decades.

SST anomaly variations affecting the SO, where the Antarctic Circumpolar Current flow associated with mesoscale eddies spawning (Cotroneo et al. 2013) plays a crucial role in advecting the SST anomalies to the east and north, are also examined in combination with SAT anomalies. Here we make use of two time series based on longitudinal $\left(0^{\circ}-360^{\circ} \mathrm{E}\right)$ and meridional $\left(60^{\circ}-70^{\circ} \mathrm{S}\right)$ averages of the monthly SST (hereinafter SST index) and SAT (hereinafter SAT index) anomalies. The investigation of these two fields is crucial to cast further light on the interpretation of trends associated with the climate indices and the TSIC index.

\section{Spatial patterns of climate modes}

As stated before, the climate modes investigated are formulated through different atmospheric variables and have unique physical characteristics and dynamical mechanisms of generation. As a consequence, these patterns are totally independent of each other. We present the spatial patterns of each of these drivers in the $\mathrm{SH}$ through linear regression coefficients. In detail, each geophysical field, from which the climate index is derived, is regressed onto the climate index itself (Fig. 1). Even though regressions are calculated from different variables and cannot be compared against each other, these indicate the geographical locations where each climate mode has the strongest impact.

The SAM (Fig. 1a) reflects out-of-phase SLP anomalies on Antarctica and in the midlatitudes, also presenting a larger impact on the Amundsen-Bellingshausen sectors. The SAO is a symmetric pattern of out-of-phase T500 anomalies between the Antarctic coastal region and midlatitude areas, and it has a larger influence over the regions (Fig. 1b). While the SLP anomalies on Antarctica largely contribute to the SAM variability, the SAO pattern, on the contrary, strongly depends on the coastal T500 variability, this latter being a key resource in the maintenance of the meridional thermal gradient between the middle and high latitudes. The PSA and ZW3 patterns have a stronger impact over seas of the western Antarctic continent (Figs. 1c,d). Here, the meridional wind branches of the ZW3 pattern appear consistent with the geographical position of the sub-Antarctic branch of the PSA, this latter being characterized by the strong out-of-phase Z500 anomalies between the Amundsen-Bellingshausen Seas and the Weddell Sea.

To reveal the importance of these climate modes in the atmosphere, correlation patterns are calculated correlating the monthly anomaly time series of climate indices with the monthly SLP anomalies (Fig. 2). Before calculating correlations, the climate indices are first detrended, and then these, together with the SLP anomalies, are aggregated into 3-month running means to suppress the noise that might still be present at the monthly scale. This procedure also absorbs some of the impact of the spatial phase shifts experienced by climate patterns, and the net effect is a reduction in the size of climate indices during the time of movement, but little influence on their sign.

We note that the PSA pattern has the strongest impact in the southeastern Pacific sector (Fig. 2c), where it shows negative and strong correlations exceeding $r=0.8$ $(p<0.01)$, while the two centers of positive correlations located in the southwestern Pacific and southwestern 
(a) Correlation Pattern Upon SAMI

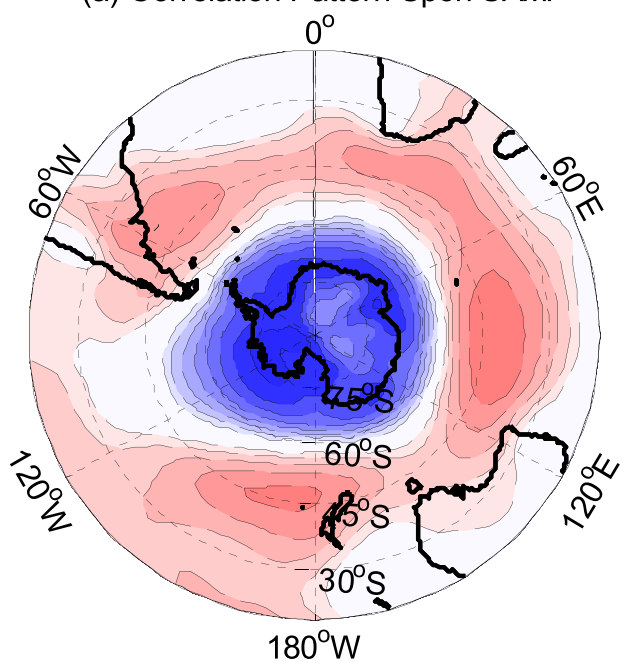

(c) Correlation Pattern Upon PSA index

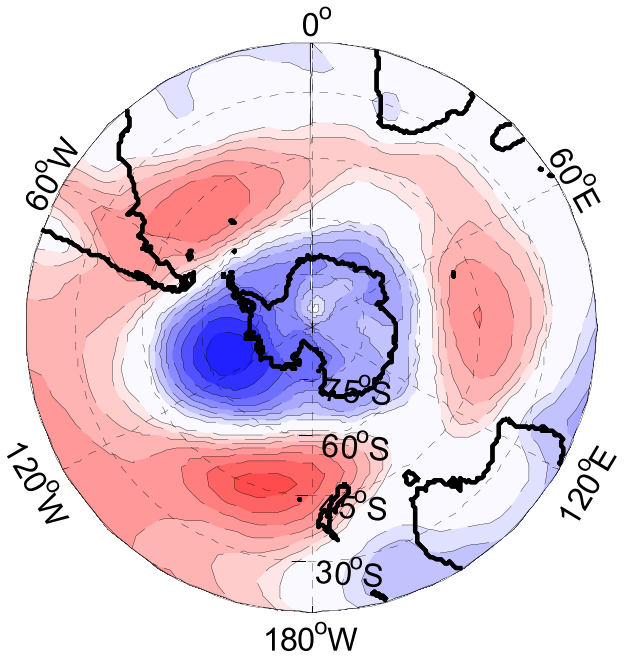

(b) Correlation Pattern Upon SAO index

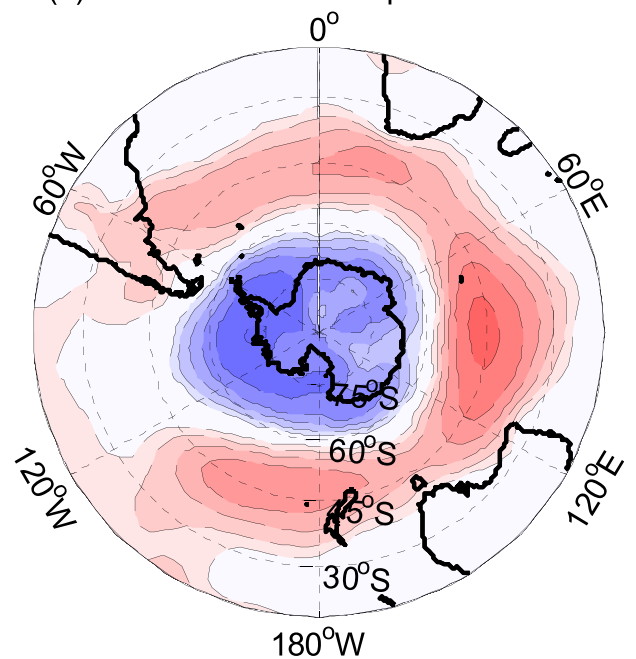

(d) Correlation Pattern Upon ZW3 index

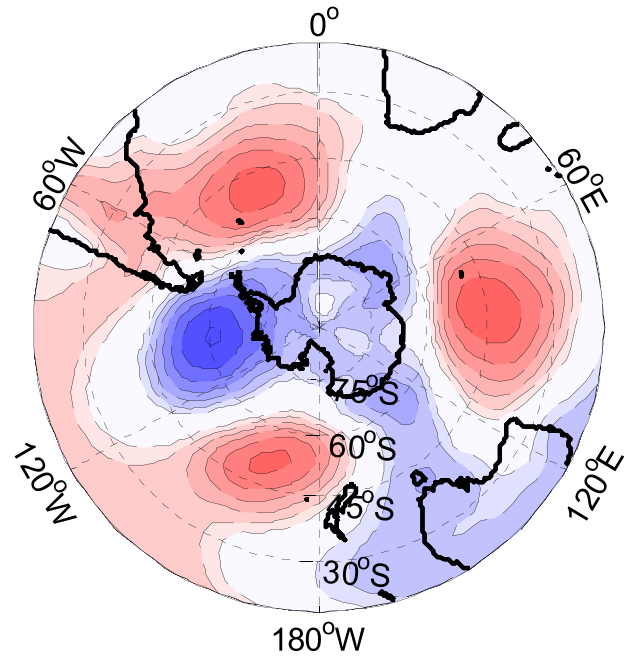

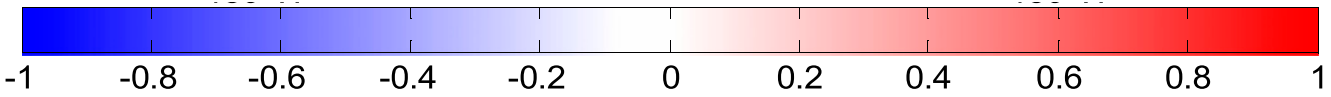

FIG. 2. Distribution of correlation coefficients between the SLP anomalies and detrended anomalies of the (a) SAMI, (b) SAO index, (c) PSA index, and (d) ZW3 index. The time series are standardized and aggregated into 3-month running means before calculating the correlations to suppress the noise still present at monthly scale and for absorbing the spatial shifts of climate modes. Correlation maps extend from $20^{\circ}$ to $90^{\circ} \mathrm{S}$ for the 32 -yr period spanning 1982-2013. Correlation coefficients from 0 to \pm 1 are displayed with positive (negative) values shaded in red (blue) with contours at an interval of 0.1 . Only correlation coefficients at $99 \%$ significance level are plotted. White indicates no significant correlation at this level.

Atlantic sectors reach maximum values of $r=0.7(p<$ $0.01)$ and $r=0.6(p<0.01)$ respectively. A portion of variability over the Indian Ocean also seems to be consistent with the existence of the PSA pattern (Fig. 2c), although the correlations reach lower values $(r=0.5, p<0.01)$ here. The spatial distribution of correlations associated with the ZW3 pattern is similar to that of the PSA even though the variability of the former mode appears to be better distributed in the $\mathrm{SH}$ (Fig. 2d). Actually, three positive centers of maxima with correlations values of $r=0.6(p<0.01)$ are observed in the South Atlantic, Indian, and Pacific sectors respectively. We argue that the co-occurrence of the correlation centers for the PSA and ZW3 patterns in the 
TABLE 1. Correlation coefficients and shared variance in parentheses between climate modes for periods 1982-2013, 1982-91, 1992-2001, and 2002-11. Monthly data series are detrended and standardized before calculating correlations. The largest correlation values are indicated by bold while the largest values of shared variance are indicated by italic.

\begin{tabular}{|c|c|c|c|c|}
\hline & SAMI & SAO index & PSA index & ZW3 index \\
\hline & \multicolumn{4}{|c|}{ 1982-2013 } \\
\hline SAMI & 1 & & & \\
\hline SAO index & $\mathbf{0 . 6 9}(66 \%)$ & 1 & & \\
\hline PSA index & $0.65(61 \%)$ & $0.62(58 \%)$ & 1 & \\
\hline \multirow[t]{2}{*}{ ZW3 index } & $0.36(34 \%)$ & $0.37(35 \%)$ & $0.68(65 \%)$ & 1 \\
\hline & \multicolumn{4}{|c|}{ 1982-91 } \\
\hline SAMI & 1 & & & \\
\hline SAO index & $\mathbf{0 . 7 0}(72 \%)$ & 1 & & \\
\hline PSA index & $0.61(53 \%)$ & $0.57(58 \%)$ & 1 & \\
\hline \multirow[t]{2}{*}{ ZW3 index } & $0.31(26 \%)$ & $0.25(25 \%)$ & $0.63(53 \%)$ & 1 \\
\hline & \multicolumn{4}{|c|}{ 1992-2001 } \\
\hline SAMI & 1 & & & \\
\hline SAO index & $\mathbf{0 . 7 3}(67 \%)$ & 1 & & \\
\hline PSA index & $0.68(69 \%)$ & $0.63(56 \%)$ & 1 & \\
\hline \multirow[t]{2}{*}{ ZW3 index } & $0.30(31 \%)$ & $0.41(38 \%)$ & $0.67(68 \%)$ & 1 \\
\hline & \multicolumn{4}{|c|}{$2002-11$} \\
\hline SAMI & 1 & & & \\
\hline SAO index & $\mathbf{0 . 7 3}(62 \%)$ & 1 & & \\
\hline PSA index & $0.68(67 \%)$ & $0.63(61 \%)$ & 1 & \\
\hline ZW3 index & $0.30(50 \%)$ & $0.41(40 \%)$ & $0.67(76 \%)$ & 1 \\
\hline
\end{tabular}

same geographical locations suggests that these two patterns may constructively interact.

While the PSA and ZW3 patterns have a negligible impact on the atmospheric pressure over Antarctica, the SAO and SAM have an important role here (Figs. 2a,b). In contrast to the $\mathrm{SAO}$, which has the largest impact on the coastal sectors of the Bellingshausen and western Antarctic Peninsula, the SAM strongly influences the atmospheric pressure for Antarctica and the central eastern South Pacific sector, where the correlation values exceed $r=0.8(p<0.01)$. We also note that the annular shape of spatial distribution associated with the SAO has a strong influence in the midlatitudes of Indian Ocean, since correlations exceed $r=0.6(p<0.01)$ here. However, except for the strength of the discussed relationships, the spatial influence of the SAM appears to be somewhat similar to that of SAO (see below).

To reveal the interrelationships between the climate patterns, we calculate the correlation coefficients and percentage values of covariability explained by climate indices (Table 1), based on detrended and standardized time series. These analyses investigate the entire period 1982-2013, and three separated decades (i.e., 1982-91, 1992-2001, and 2002-11). Results indicate that over the 32-yr period (Table 1a), the SAM-SAO relationship leads the SO variability $(r=0.69, p<0.01)$, and these two patterns share $66 \%$ of variance. Nevertheless, we note that the PSA-ZW3 relationship $(r=0.68, p<0.01)$ also has a strong role with the two patterns sharing a large fraction of variance $(65 \%)$. Consistent with these features, results for the decade 1982-91 (Table 1b) indicate that the SAM-SAO relationship leads $(r=0.70$, $p<0.01$ ), with the two patterns sharing $72 \%$ of the variance. The SAM-SAO relationship also dominates $(r=0.73, p<0.01)$ in 1992-2001 (Table 1c), although in this decade the largest percentage of covariability $(69 \%)$ is observed for the SAM-PSA relationship. We also detect a relevant connection between the PSA and ZW3 patterns $(r=0.67, p<0.01)$ since these two modes share $68 \%$ of variance in these years. Finally, in the decade 2002 11 (Table 1d), the strongest relationship is found between the SAM and SAO patterns $(r=0.73, p<0.01)$, with the two patterns sharing $62 \%$ of variance, but the largest covariability is detected for the PSA-ZW3 relationship (76\%).

Results presented above indicate that the climate indices share some variance in that these appear to be strongly intercorrelated between each other. In particular, we note that the largest correlations are found between the SAM and SAO patterns over all the investigated periods. This feature may mistakenly suggest that these two latter patterns are dependent between each other and that the SAMI and SAO index used are not indicative of the variability associated with each individual climate mode. We argue that the large correlation values between the SAM and SAO patterns are expected since the oscillation of atmospheric pressure over Antarctica and in the midlatitudes associated with the SAM variability also affects the meridional thermal gradient that is used to define the SAO variability.

However, to better detect the independence between the climate modes we find it is useful to perform power spectral analyses on detrended and standardized time series of each index. Here, the continuous wavelet transform of each index is calculated and results are displayed in Fig. 3. We note that the energy distribution associated with these indices is captured at different periodicities. In particular, significant $(p<0.05)$ energy is found for the SAMI at periods between 48 and 64 months from the early 1990s to the early 2000s, and between 16 and 32 months from the late 1990s to the early 2000s and since the late 2000s (Fig. 3a). On the contrary, the wavelet spectrum for the SAO index only shows significant $(p<0.05)$ energy at 48 months in the early 1990s and at periods between 16 and 32 months from the late 1990s to the early 2000s (Fig. 3b). We also observe that spectra for the SAMI and SAO index show substantial differences on the seasonal time scale (cf. Figs. $3 a$ and $3 b$ ), thus indicating the independence between these two modes in the atmospheric circulation. 

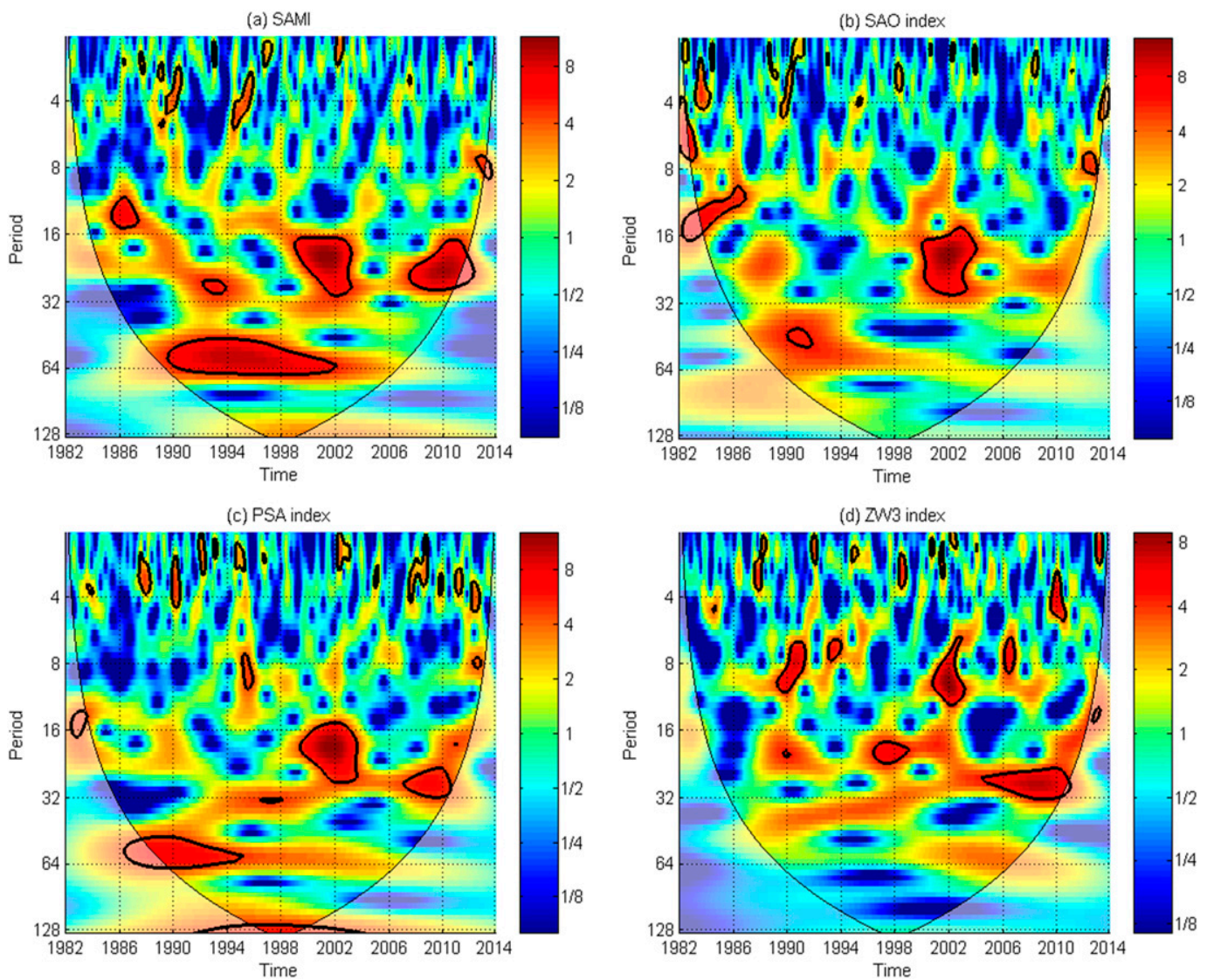

FIG. 3. Continuous wavelet power spectrum of the (a) SAMI, (b) SAO index, (c) PSA index, and (d) ZW3 index. The thick black contour designates the $95 \%$ significance level against red noise and the cone of influence (COI). The climate indices are detrended and standardized before the calculation of spectra. The $x$ axis is time and the $y$ axis is the period in months.

The wavelet spectrum for the PSA index appears to be somewhat consistent with that of the SAMI as it shows significant $(p<0.05)$ energy at periods between 48 and 64 months from the late 1980s to the mid-1990s and at periods between 16 and 32 months from the late 1990s to the mid-2000s, and in the late 2000s (Fig. 3c). Finally, the wavelet spectrum for the ZW3 index shows significant $(p<0.05)$ energy at periods around 24 months in the late 1990s and at periods around 32 months in the mid to late 2000s (Fig. 3d). We argue that these findings further differentiate one climate mode from the other in agreement with YL08.

To further examine the interrelationships between the climate modes, we construct cross-wavelet spectra combining in pairs the climate indices to reveal how one climate mode influences, or is influenced by, the other, and results are shown in Fig. 4. Before the calculation of spectra, the climate indices are detrended and standardized. We note that a large portion of significant $(p<$ $0.05)$ shared power is associated with the covariability among the SAM, SAO, and PSA patterns from the late 1980 s to the late 1990s and it is concentrated on time scales between 48 and 64 months (Figs. 4a,b,d). We also observe that in the 2000 decade significant $(p<0.05)$ energy is shared among the four climate patterns investigated on time scales ranging from 16 to 32 months (Figs. 4a-f), except perhaps for a brief interval around the mid-2000s, when the covariability among the SAM, SAO, and PSA patterns (Figs. 4a,b,d) appears to be insignificant.

\section{Impact from climate modes on sea ice concentration}

To quantify the impact from climate modes on the SIC distribution around Antarctica, regression patterns are calculated by regressing the unfiltered and unnormalized SIC anomalies onto the four climate indices based on detrended, deseasonalized, and standardized monthly anomalies, and results are shown in Figs. 5a-d. Regression 

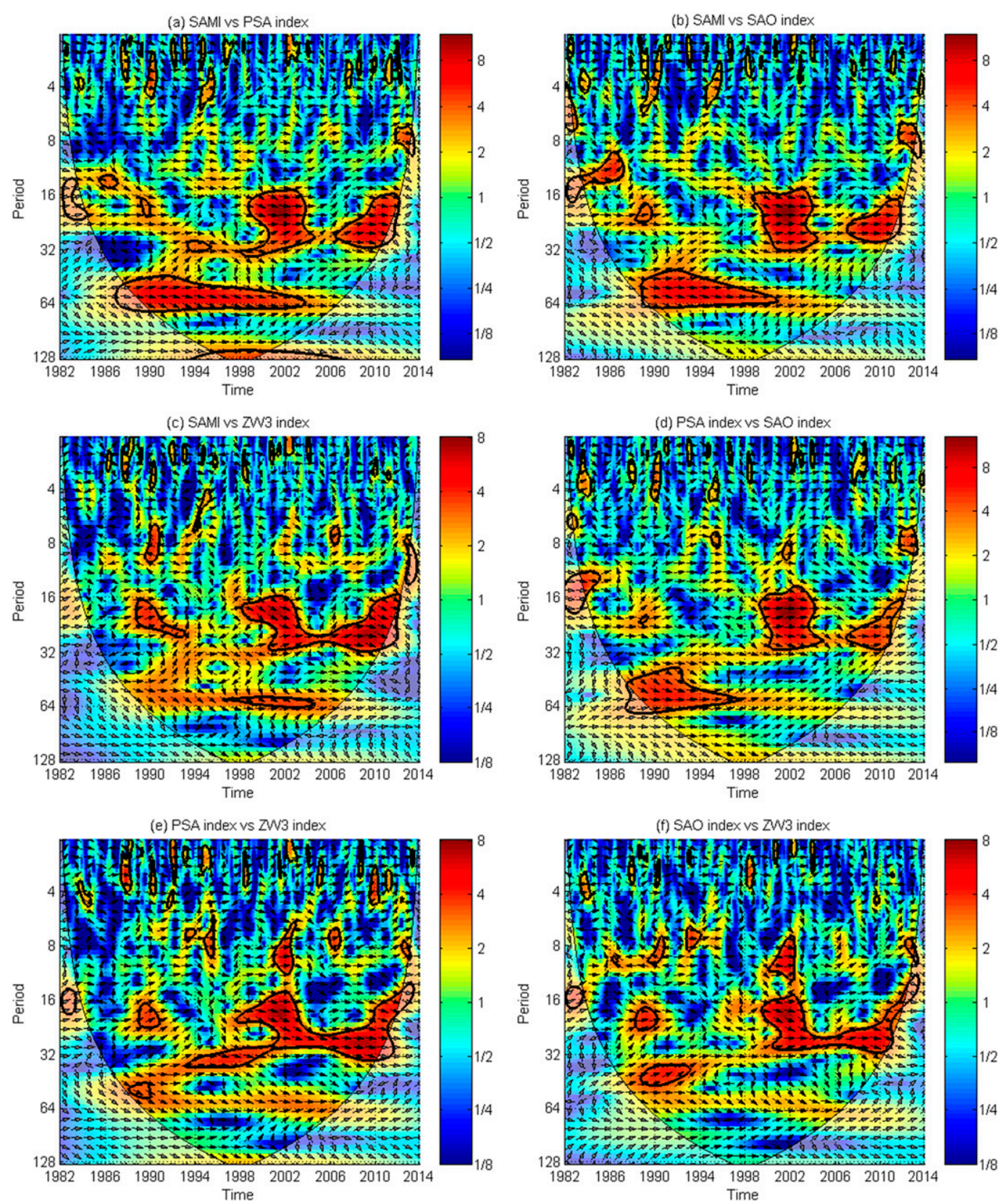

FIG. 4. Cross wavelet transform of the (a) SAMI and PSA index, (b) SAMI and SAO index, (c) SAMI and ZW3 index, (d) PSA index and SAO index, (e) PSA index and ZW3 index, and (f) SAO index and ZW3 index. The thick black contour designates the $95 \%$ significance level against red noise. The relative phase relationship is shown as arrows (with in-phase pointing right and anti-phase pointing left, and the first index leading the second by $90^{\circ}$ pointing straight down). The climate indices are detrended and standardized before the calculation of spectra. The $x$ axis is time and the $y$ axis is the period in months.

analyses are also extended to the SST (Figs. 5e-h) and SAT (Figs. 5i-l) anomalies to reveal the impact from climate patterns at level of the ocean-atmospheric boundary layer (i.e., where complex physical and dynamic mechanisms influence the growth and melting of the seasonal sea ice coverage). As discussed above, the influences from climate modes are heterogeneously distributed showing similarities to each other as the indices representing these modes share some variances. Nevertheless, the signatures of SAM and SAO patterns appear to be more zonally distributed than those of PSA and ZW3, whose influences have a 


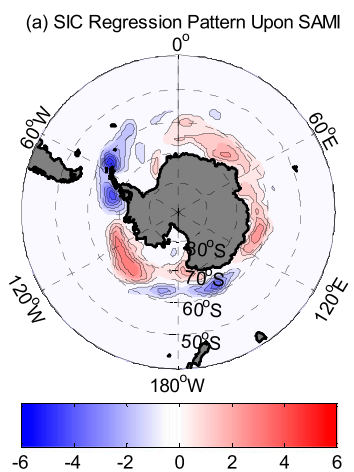

(e) SST Regression Pattern Upon SAMI

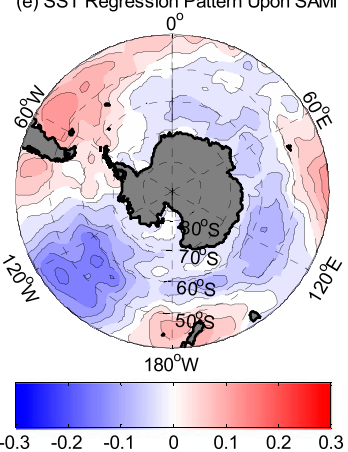

(i) SAT $2 m$ Regression Pattern Upon SAM

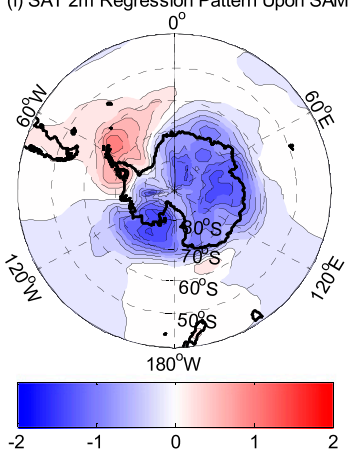

(b) SIC Regression Pattern Upon SAO index

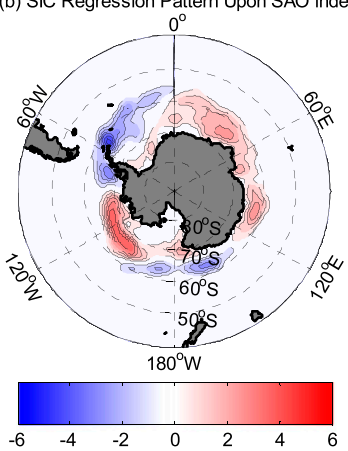

(f) SST Regression Pattern Upon SAO index

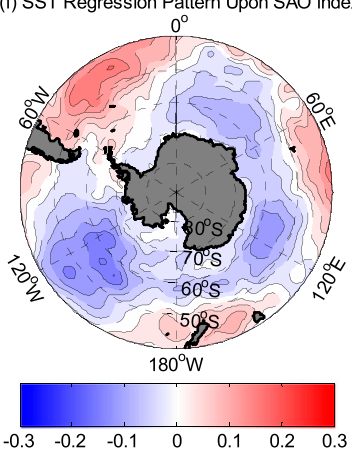

(c) SIC Regression Pattern Upon PSA index

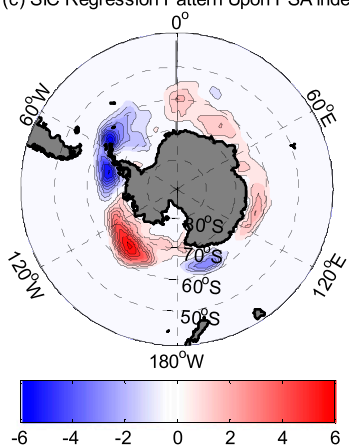

(g) SST Regression Pattern Upon PSA index
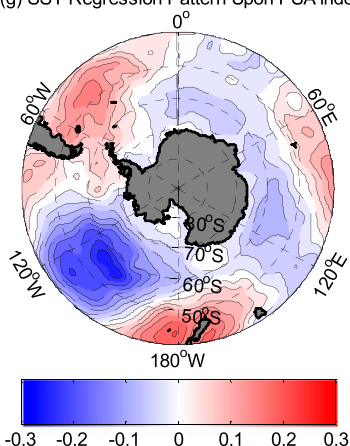

(d) SIC Regression Pattern Upon ZW3 index

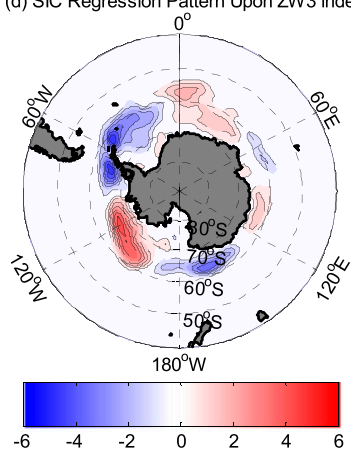

(h) SST Regression Pattern Upon ZW3 index
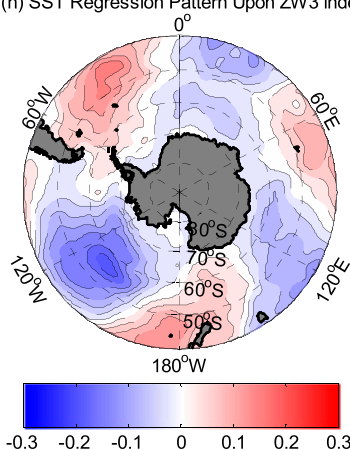

(j) SAT $2 m$ Regression Pattern Upon SAO index (k) SAT 2m Regression Pattern Upon PSA index (I) SAT $2 m$ Regression Pattern Upon ZW3 index

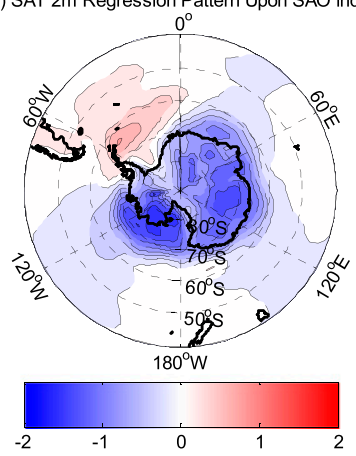

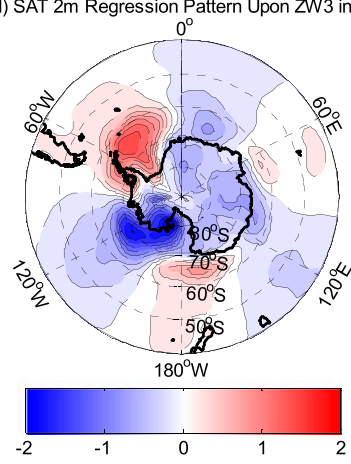

FIG. 5. Spatial pattern generated by regressing the unnormalized and unfiltered (a) SIC anomalies onto the SAMI. (b)-(d) As in (a), but for the SAO index, PSA index, and ZW3 index, respectively. (e) As in (a), but for SST anomalies. (f)-(h) As in (e), but for the SAO index, PSA index, and ZW3 index, respectively. (i) As in (a), but for SAT anomalies. (j)-(1) As in (i), but for the SAO index, PSA index, and ZW3 index, respectively. The climate indices are detrended and standardized before the regression. Each map extends from $40^{\circ}$ to $90^{\circ} \mathrm{S}$ for the 32-yr period spanning 1982-2013. White-to-red (blue) colors indicate positive (negative) regression coefficients, with contours at intervals of $0.6 \%, 0.03^{\circ} \mathrm{C}$, and $0.2^{\circ} \mathrm{C}$ per 1 std dev of each climate index for (a)-(d), (e)-(h), and (i)-(l), respectively.

more regional impact in the Western Hemisphere (Figs. 5a-1).

The SAO has the strongest impact on the SSTs in the Indian sector (Fig. 5f), and it more strongly affects the SIC and SAT (Figs. 5b,j) anomalies than the SAM (Figs. 5a,i) in the central Pacific sector. Conversely to the SAO, the SAM has a stronger impact on the SST (cf. Figs. 5e,f) and SAT (cf. Figs. 5i,j) anomaly distribution surrounding the Antarctic Peninsula and over the western Weddell and eastern Bellingshausen Seas. During positive SAM and SAO phases, the SIC is observed to increase near the
Antarctic edge except in the longitude-latitude domain of $130^{\circ} \mathrm{E}-140^{\circ} \mathrm{W}$ and $60^{\circ}-65^{\circ} \mathrm{S}$ of the western Pacific sector, and in the eastern Bellingshausen-western Antarctic Peninsula and western Atlantic sectors, where significant reductions are observed (Figs. 5a,b). We also note that influences of the SAM on the SIC are a little stronger than those of the SAO in the western Pacific, western Antarctic Peninsula, and western Weddell sectors, although these are less extended here (cf. Figs. 5a and 5b).

The PSA dominates in the South Pacific and western Atlantic sectors, where the pattern shows out-of-phase SIC 
(Fig. 5c), SST (Fig. 5g), and SAT (Fig. 5k) regressions consistent with the Antarctic dipole (Yuan 2004). Influences from the ZW3 (Figs. 5d,h,l) are similar and comparable in magnitude to those of the PSA (Figs. 5c,g,k), although the signature of the former is more evenly distributed among the three branches. Conversely to the impact from the SAM and SAO, the ZW3 more strongly affects the SIC (cf. Figs. 5a,b and 5d) and SAT (cf. Figs. 5i,j and 5l) distributions in the central Pacific, eastern Bellingshausen-western Antarctic Peninsula, and western Atlantic sectors. We also note that the influences from the ZW3 are the strongest in the western Pacific sector (Figs. 5d,h,l). Positive PSA and ZW3 phases are associated with the increase of the SIC in the eastern Indian, central Pacific, eastern Atlantic, and western Indian sectors, but a significant reduction of concentrations is observed in the western Pacific, eastern Bellingshausen-western Antarctic Peninsula, and western Atlantic sectors (Figs. 5c,d).

Results on the SIC presented above are consistent with those shown in YL08's paper, where they identified the strength of the climate mode-sea ice relationships for ice lagging 2 months by making use of interannual correlations (period $>13$ months) over a shorter period (1978-2002). This means that, even if our regressions (Fig. 5) are calculated at 0 months lag and are based on unfiltered monthly anomalies of SIC, SST, SAT, and climate indices, the subannual variability in the climate mode-sea ice relationships is detected.

To quantify the impact from climate modes on SIC, SST, and SAT anomalies on the decadal scale, regression analyses are conducted on separated decades (i.e., 198291, 1992-2001, and 2002-11). Also here, the climate indices are standardized and detrended before calculating regressions. In the decade 1982-91, the SAO pattern shows the strongest impact on the SIC (Fig. 6b), SST (Fig. 7b), and SAT (Fig. 8b) anomalies in the Indian sector, and it also dominates the SIC in the western Pacific sectors (Fig. 6b), although a little influence on the SST (Fig. 7b) and SAT (Fig. 8b) anomalies is observed here, as these two fields appear to be more strongly affected by the impacts from PSA (Figs. 7c and 8c) and ZW3 (Figs. 7d and 8d). Noteworthy impacts from PSA and ZW3 on the SIC (Figs. 6c,d), SST (Figs. 7c,d), and SAT (Figs. 8c,d) anomalies are observed in the central Pacific, eastern Bellingshausen-western Antarctic Peninsula, and eastern Atlantic sectors.

In contrast to these features, somewhat different variations are observed in the decade 1992-2001. We note that impacts from SAM and SAO on the SIC (Figs. 6e,f) are strengthened in the central Pacific sector, although the signatures of PSA and ZW3 (Figs. 6g,h) still lead here, also having the strongest influence on the SST (Figs. 7g,h) and SAT (Figs. 8g,h) anomalies. The PSA also dominates the
SIC (Fig. 6g), SST (Fig. 7g), and SAT (Fig. 8g) anomalies in the eastern Bellingshausen and western Antarctic Peninsula sectors, although somewhat strong influences from the SAM (Figs. 6e, 7e, and 8e) and ZW3 (Figs. 6h, 7h, and 8h) are also observed in these two sectors. Impacts from the PSA on SIC (Fig. 6g) and SST (Fig. 7g) anomalies, and from the ZW3 on SAT (Fig. 8h) anomalies, lead in the Weddell sector, and are found in association with strong and noteworthy SAM (Figs. 6e, 7e, and 8e) and SAO (Figs. 6f, 7f, and $8 \mathrm{f}$ ) signatures. We also note that important variations in SIC (Fig. 6e), SST (Fig. 7e), and SAT (Fig. 8e) come from the influence of the SAM in the eastern Indian sector, and from that of the ZW3 (Figs. 6h, 7h, and 8h) in the western Pacific sector.

In the decade 2002-11, important changes affect the variability surrounding Antarctica. We note that the impact of the PSA dominates the SIC (Fig. 6k), SST (Fig. 7k), and SAT (Fig. 8k) signals in the eastern Bellingshausen and western Antarctic Peninsula, although here the signature of the pattern is weaker than that observed in the previous decade. However, in these two sectors, influences from the SAM (Figs. 6i, 7i, and 8i) appear to be somewhat relevant since the associated regression values are comparable in magnitude to those found for the PSA. The SAM also dominates the SIC (Fig. 6i) in the central Pacific sector, but here a reduced influence is observed on SAT anomalies, whose strongest variations are induced by the PSA (Fig. 8k). We also note that the SAM and PSA patterns have comparable influences on the SST anomalies in the central Pacific sector (Figs. 7i,k). Large influences from the SAM and ZW3 on the SIC (Figs. 6i,1) are detected in the western Pacific, where the ZW3 also dominates the SST and SAT variations (Figs. 71 and 81 ). We note that impacts from the SAO on SIC (Fig. 6j) and SST (Fig. 7j) anomalies are relevant in the eastern Atlantic and Indian sectors. However, in the western Indian sector, the influences from the SAM and ZW3 are comparable in magnitude and dominate the SAT anomalies (Figs. 8i,1).

In summary, the influence of climate patterns on the SIC, SST, and SAT anomalies is found to be somewhat strengthened across the SO in the last two decades. In particular, we note the presence of more zonally distributed positive (negative) SIC (SST) anomalies around Antarctica during the last decade.

\section{Trends in sea ice concentration and climate modes}

Time series of SST, SAT, TSIC, and climate indices are examined through trend analysis. These series are standardized and then fitted to the line of best fit using the least squares method. The strength of trends per 


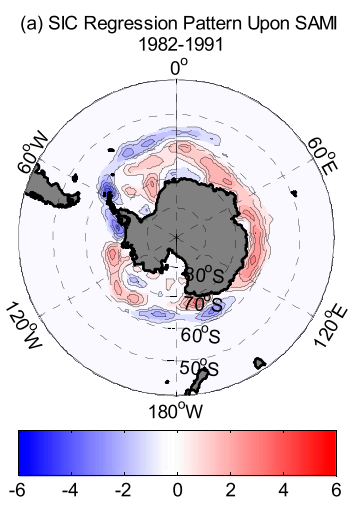

(e) SIC Regression Pattern Upon SAMI
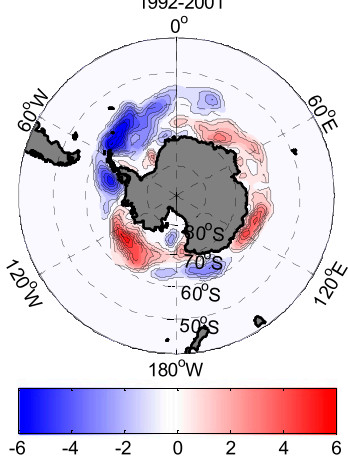

(i) SIC Regression Pattern Upon SAMI
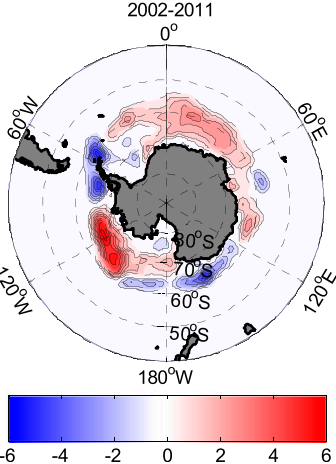

(b) SIC Regression Pattern Upon SAO index
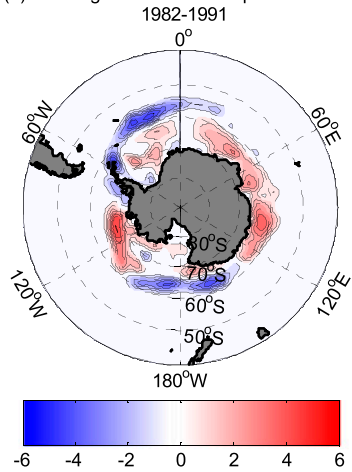

(f) SIC Regression Pattern Upon SAO index
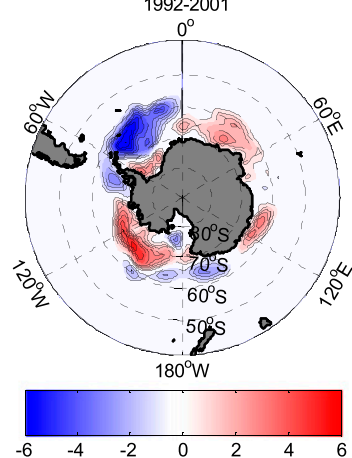

(j) SIC Regression Pattern Upon SAO index

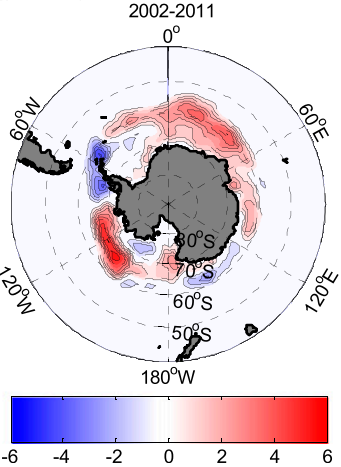

(c) SIC Regression Pattern Upon PSA index 1982-1991

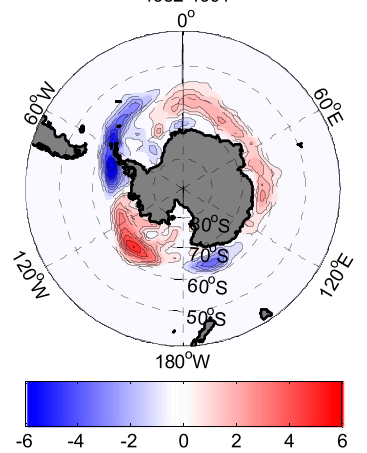

(g) SIC Regression Pattern Upon PSA index

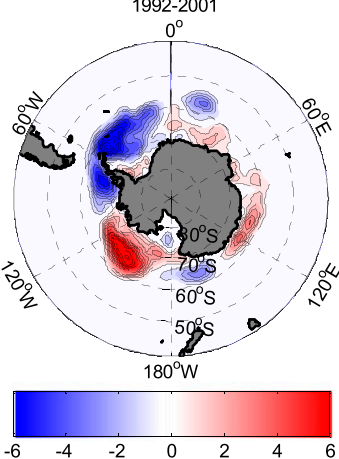

(k) SIC Regression Pattern Upon PSA index

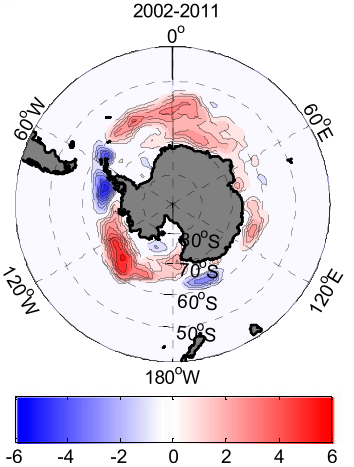

(d) SIC Regression Pattern Upon ZW 3 index

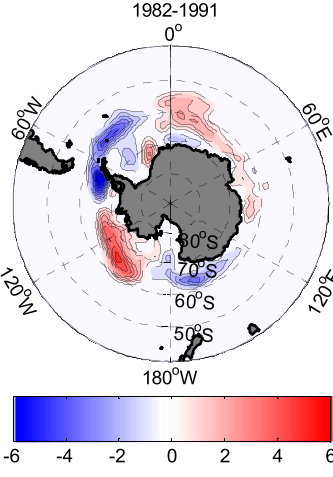

(h) SIC Regression Pattern Upon ZW3 index

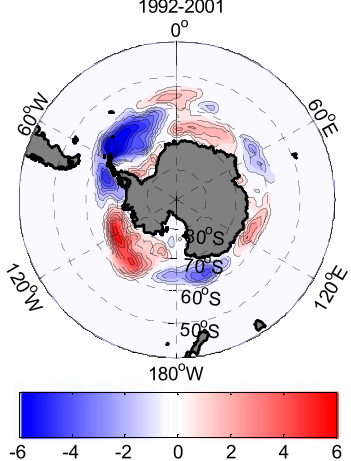

(I) SIC Regression Pattern Upon ZW3 index

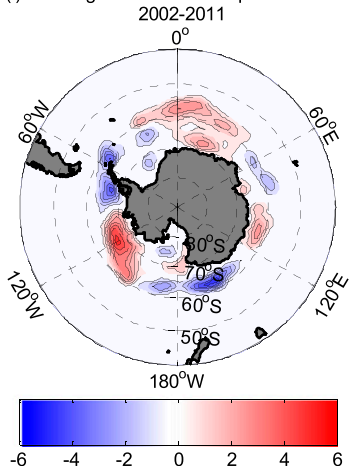

FIG. 6. (a) Spatial pattern generated by regressing the unnormalized and unfiltered SIC anomalies onto the SAMI over the decade 198291. (b)-(d) As in (a), but for the SAO index, PSA index, and ZW3 index, respectively. (e) As in (a), but for 1992-2001. (f)-(h) As in (e), but for the SAO index, PSA index, and ZW3 index, respectively. (i) As in (a), but for 2002-11. (j)-(1) As in (i), but for the SAO index, PSA index, and ZW3 index, respectively. The climate indices are detrended and standardized before the regression, and each map extends from $40^{\circ}$ to $90^{\circ} \mathrm{S}$. White-red (white-blue) colors indicate positive (negative) regression coefficients, with contours at intervals of $0.6 \%$ per 1 std dev of each climate index.

decade is calculated by the difference of the two endpoints of these straight lines divided by 3.1 , which is the number of decadal intervals.

\section{a. The Mann-Kendall test}

A number of parametric and nonparametric statistical tests exist to assess the significance of trends in time series. A common requirement of these two classes of trend tests is that the data be independent, since, as stated by Cox and Stuart (1955), "positive serial correlation among the observations would increase the chance of significant answer, even in the absence of a trend" (p. 95). Nevertheless, parametric trend tests, although more powerful, require the data to be normally distributed, a feature rarely true for climate time series, and are more sensitive to outliers. On the contrary, nonparametric trend tests, being a function of the ranks of the observations rather than their actual values, are not affected by the distribution of data and are less sensitive to outliers (Hirsch et al. 1982; Hamed and 


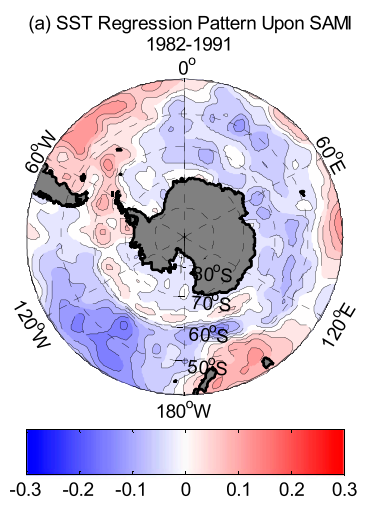

(e) SST Regression Pattern Upon SAMI
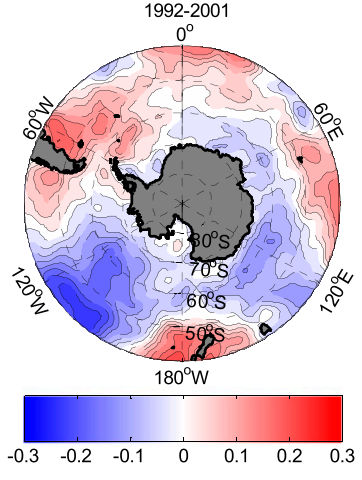

(i) SST Regression Pattern Upon SAMI 2002-2011
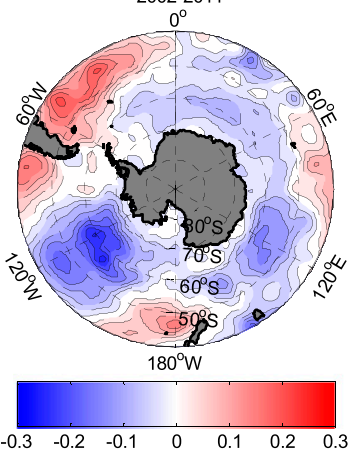

(b) SST Regression Pattern Upon SAO index

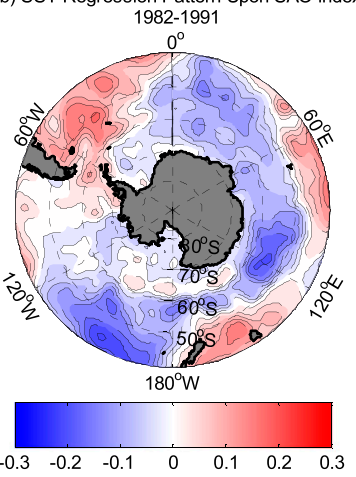

(f) SST Regression Pattern Upon SAO index
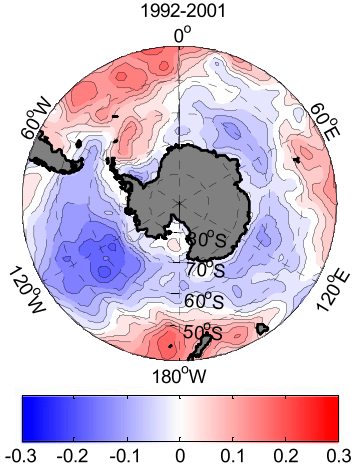

(j) SST Regression Pattern Upon SAO index

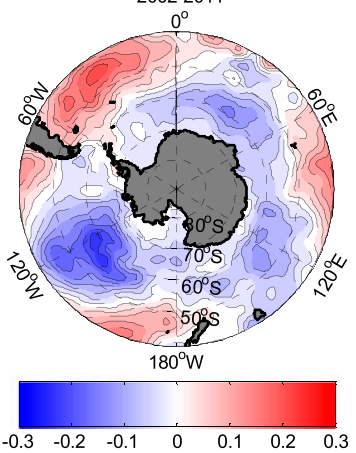

(c) SST Regression Pattern Upon PSA index

1982-1991
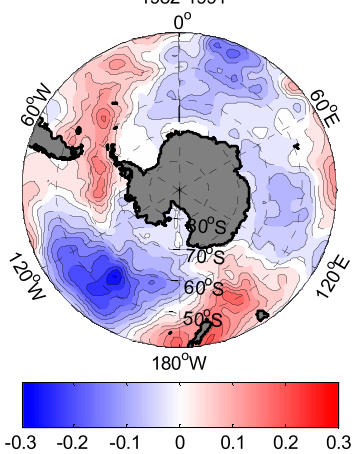

(g) SST Regression Pattern Upon PSA index
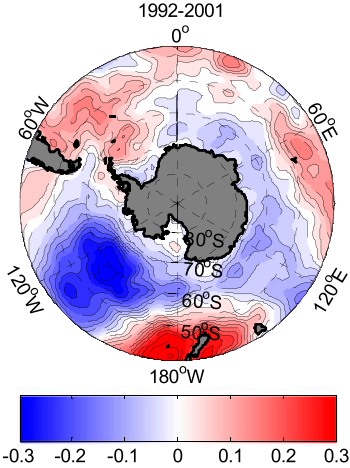

(k) SST Regression Pattern Upon PSA index 2002-2011

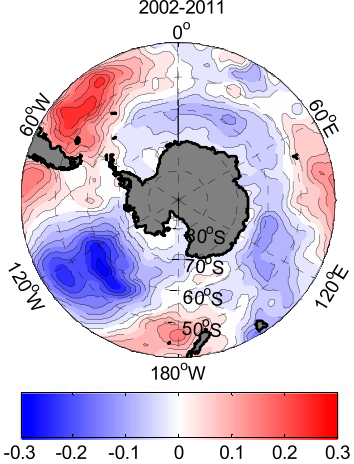

(d) SST Regression Pattern Upon ZW3 index
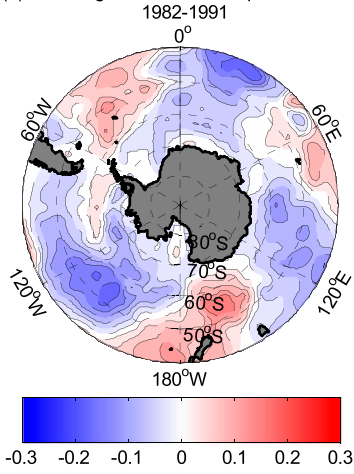

(h) SST Regression Pattern Upon ZW3 index

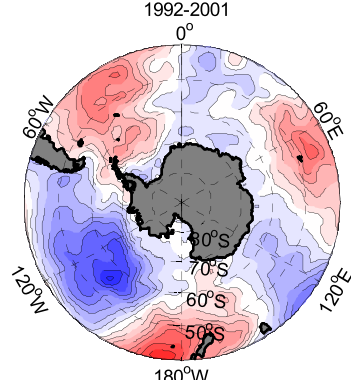

$180^{\circ} \mathrm{W}$

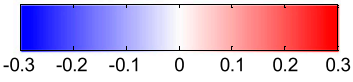

(I) SST Regression Pattern Upon ZW3 index 2002-2011

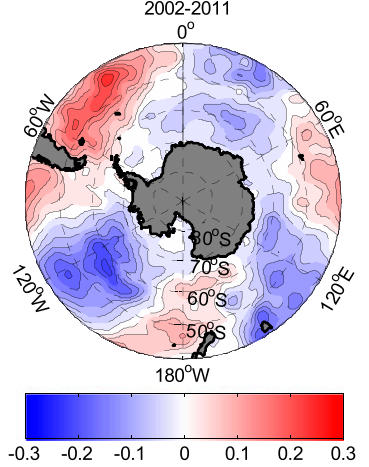

FIG. 7. (a) Spatial pattern generated by regressing the unnormalized and unfiltered SST anomalies onto the SAMI over the decade 1982-91. (b)-(d) As in (a), but for the SAO index, PSA index, and ZW3 index, respectively. (e) As in (a), but for 1992-2001. (f)-(h) As in (e), but for the SAO index, PSA index, and ZW3 index, respectively. (i) As in (a), but for 2002-11. (j)-(l) As in (i), but for the SAO index, PSA index, and ZW3 index, respectively. The climate indices are detrended and standardized before the regression, and each map extends from $40^{\circ}$ to $90^{\circ} \mathrm{S}$. White-red (white-blue) colors indicate positive (negative) regression coefficients, with contours at intervals of $0.03^{\circ} \mathrm{C}$ per 1 std dev of each climate index.

Rao 1998). Here, the significance levels (SLs) of trends are calculated by the application of the nonparametric Mann-Kendall (MK) trend test (Mann 1945; Kendall 1955; Kendall and Stuart 1967) modified to account for autocorrelation on the time series (Hamed and Rao 1998; Blain 2013). This trend test, in the presence of positive autocorrelation in the data, reduces the probability of detecting trends when actually none exist (and vice versa); in addition, its accuracy in terms of empirical SL is superior to that of the original MK trend test without any loss of power (Hamed and Rao 1998). The power of this test is an increasing function of the slope of trend, sample size, and preassigned significance level (a threshold of probability agreed before the test is conducted) while, on the contrary, it is a decreasing function of the variation of the time series (Yue et al. 2002).

In our applications the pre-assigned level chosen for the MK test is $\alpha=0.01$, corresponding to the $99 \%$ SL. The test, in turn, provides a $p$ value, which is the probability, under the null hypothesis, of obtaining a 


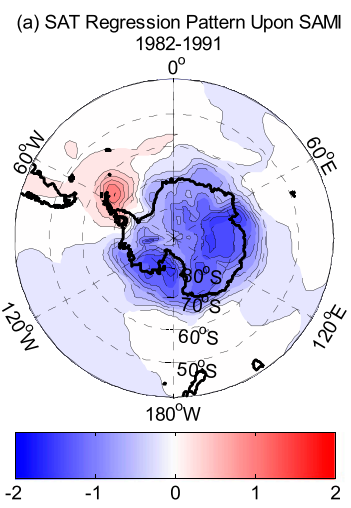

(e) SAT Regression Pattern Upon SAMI
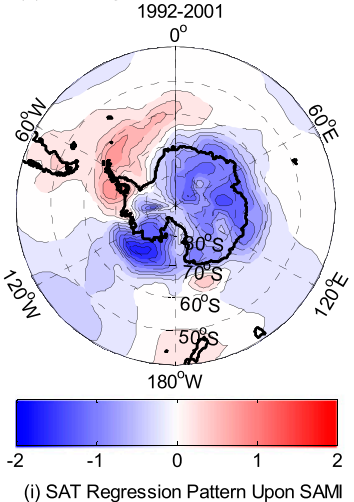

(i) SAT Regression Pattern Upon SAMI
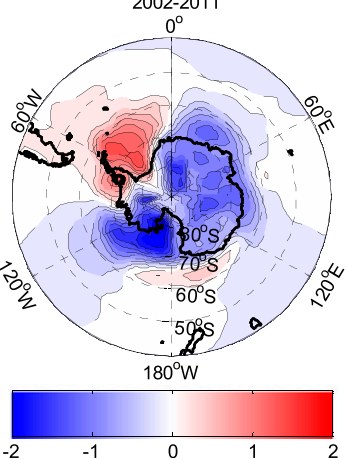

(b) SAT Regression Pattern Upon SAO index 1982-1991

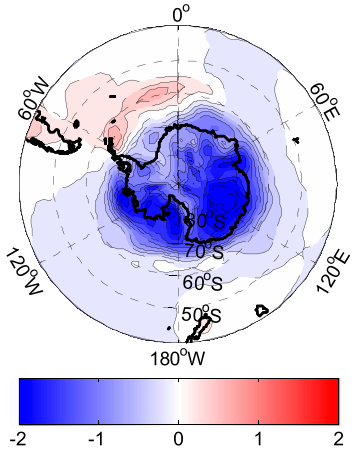

(f) SAT Regression Pattern Upon SAO index 992-2001
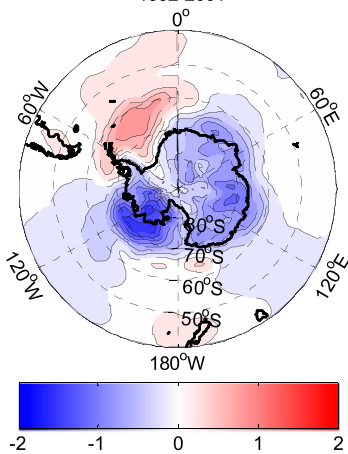

(j) SAT Regression Pattern Upon SAO index
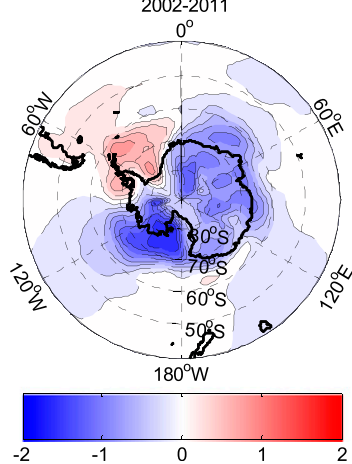

(c) SAT Regression Pattern Upon PSA index 1982-1991

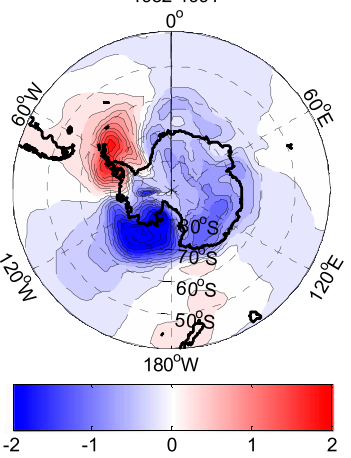

(g) SAT Regression Pattern Upon PSA index 992-2001

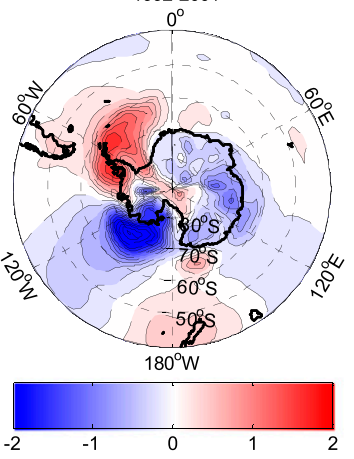

(k) SAT Regression Pattern Upon PSA index

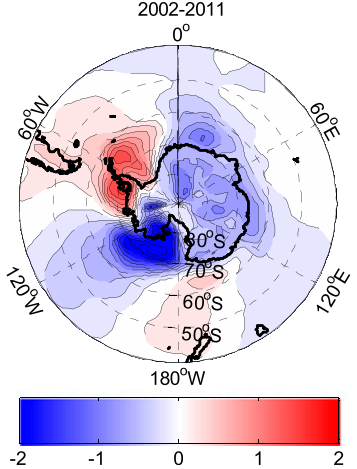

(d) SAT Regression Pattern Upon ZW3 index 1982-1991

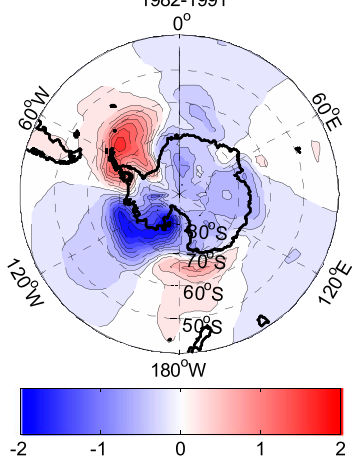

(h) SAT Regression Pattern Upon ZW3 index
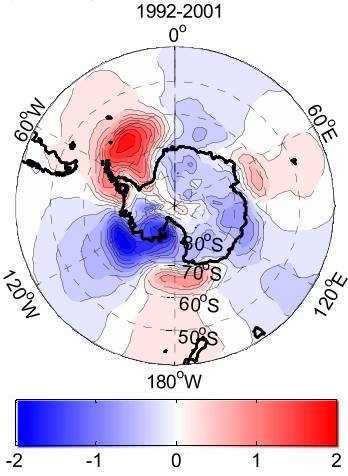

(I) SAT Regression Pattern Upon ZW3 index 2002-2011

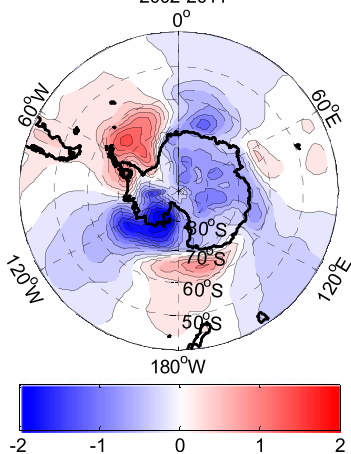

FIG. 8. (a) Spatial pattern generated by regressing the unnormalized and unfiltered SAT anomalies onto the SAMI over the decade 1982-91. (b)-(d) As in (a), but for the SAO index, PSA index, and ZW3 index, respectively. (e) As in (a), but for 1992-2001. (f)-(h) As in (e), but for the SAO index, PSA index, and ZW3 index, respectively. (i) As in (a), but for 2002-11. (j)-(l) As in (i), but for the SAO index, PSA index, and ZW3 index, respectively. The climate indices are detrended and standardized before the regression, and each map extends from $40^{\circ}$ to $90^{\circ} \mathrm{S}$. White-red (white-blue) colors indicate positive (negative) regression coefficients, with contours at intervals of $0.2^{\circ} \mathrm{C}$ per 1 std dev of each climate index.

value of the test statistic as extreme or more extreme than the value computed from the sample. If the $p$ value is lesser than alpha, the test rejects the null hypothesis, and so the trend appears to be insignificant. On the contrary, if the $p$ value is larger than alpha, there is insufficient evidence to reject the null hypothesis, and so the trend appears to be significant.

Table 2 illustrates the magnitude and the SL of these trends on the annual and seasonal scales. We note that the SST and TSIC indices show robust and highly significant $(p<0.01)$ annual trend values of opposite sign. These two trends indicate that the surface of the seas surrounding Antarctica has gradually cooled, showing lower than normal temperatures, and that, consistent with these variations, more sea ice has been produced during the past three decades. The SL of the upward annual TSIC index trend is consistent with that found by Simmonds (2015, hereinafter S15) for the annual SIE trend over the 35-yr period spanning 1979-2013, and with that found by Parkinson and Cavalieri (2012, hereinafter PC12) for the 
TABLE 2. Annual and seasonal linear trends (changes per decade) in standardized climate indices and TSIC, SAT, and SST indices time series for the 32-yr period spanning from January 1982 to December 2013. The statistical significance of trends is derived by the application of the Mann-Kendall test modified to account for autocorrelation on the time series (Hamed and Rao 1998; Blain 2013) and is indicated by the typeface: bold (99\%), bold italic $(95 \%)$, and italic $(90 \%)$.

\begin{tabular}{lcrrrr}
\hline \hline & \multicolumn{5}{c}{ Mann-Kendall trend test } \\
\cline { 2 - 6 } & Annual & \multicolumn{1}{c}{ MAM } & \multicolumn{1}{c}{ JJA } & \multicolumn{1}{c}{ SON } & \multicolumn{1}{c}{ DJF } \\
\hline SAMI & $\mathbf{0 . 1 7 2 2}$ & $\mathbf{0 . 2 4 4 4}$ & 0.1101 & 0.0075 & $\mathbf{0 . 3 2 1 4}$ \\
SAO index & $\mathbf{0 . 1 5 6 8}$ & $\mathbf{0 . 2 1 0 5}$ & 0.0716 & -0.0905 & $\mathbf{0 . 4 3 1 0}$ \\
PSA index & $\mathbf{0 . 1 7 4 1}$ & $\mathbf{0 . 2 6 4 1}$ & 0.0924 & 0.0885 & 0.2461 \\
ZW3 index & $\mathbf{0 . 1 2 1 9}$ & 0.1820 & 0.1035 & 0.1087 & 0.0897 \\
SAT index & 0.1333 & 0.1417 & $\mathbf{0 . 3 8 8 7}$ & $\mathbf{0 . 4 6 2 2}$ & $\mathbf{- 0 . 4 6 3 6}$ \\
SST index & $\mathbf{- 0 . 4 9 8 1}$ & $\mathbf{- 0 . 3 4 8 5}$ & $\mathbf{- 0 . 6 3 5 1}$ & $\mathbf{- 0 . 5 9 1 5}$ & $\mathbf{- 0 . 4 0 1 8}$ \\
TSIC index & $\mathbf{0 . 4 8 9 9}$ & 0.2850 & 0.4916 & 0.6148 & $\mathbf{0 . 5 5 3 2}$ \\
\hline
\end{tabular}

annual SIA and SIE trends calculated over the period 1979-2010. As for the climate indices, the highest SL is detected for the upward annual trend of the SAMI, SAO, and PSA indices $(p<0.01)$ and the lowest for the ZW3 index $(p<0.05)$ (Table 2).

The upward annual trend of the SAMI suggests the presence of stronger westerly winds in association with a major northward contraction of the polar vortex, resulting in an increased insulation and cooling of the Antarctic continent and the surrounding seas (Thompson and Solomon 2002). This could result from the deepening and strengthening of low pressure over and around Antarctica or from the presence of higher pressure conditions in the midlatitudes. The upward annual SAO index trend indicates the strengthening of the thermal gradient between the middle and high latitudes of the $\mathrm{SH}$, and this could result from changes of SAM variability discussed above, since the SAM and SAO are two highly covariant patterns (YL08). We also argue that the upward SAO index trend could indicate the presence of more sea ice around Antarctica, this being strongly influenced by variations in the strength and latitudinal position of the CPT. The upward SAO index trend detected here is consistent with results of YL08, who found an upward annual trend for the SAO index in SLP anomalies. However, they pointed out that care should be taken in the interpretation of this trend, since it could partially come from the spurious long-term reduction of SLP near $65^{\circ} \mathrm{S}$ in the NCEP-NCAR reanalysis data (Hines et al. 2000). This is not the case here because our SAO index is derived by making use of temperature anomalies in the midtroposphere. However, consistent with results of YL08, our upward SAO index trend does not indicate the weakening of the SAO signal since the 1970s, as described in the early studies (van Loon et al. 1993; Hurrell and van Loon 1994).
As for the PSA index, its trend is consistent both in significance and in magnitude with the PSA trend value reported by YL08, and this could indicate the deepening of the LPC in the Amundsen Sea, the increase of atmospheric pressure in the South Pacific and Atlantic sectors, or probably both conditions. These findings could also be a consequence of an increased occurrence of La Niña events in the tropical Pacific (Yuan and Martinson 2001; Yuan 2004). Although the SAM and ENSO trends cannot explain completely the sea ice variations recorded in the western Antarctic Peninsula (Liu et al. 2004), according to Thompson and Solomon (2002) the upward SAMI trend found on the annual scale could be the main cause for the warming of this region. Actually, the western wind anomaly brings maritime air onto the Antarctic Peninsula, which is also surrounded by a warmer ocean than the peninsula itself. As a result, increased westerlies induce an enhanced heat transport onto the peninsula, which affects the sea ice retreat over this region.

The annual trend detected for the ZW3 index requires attention. YL08 found a downward and highly significant $(p<0.01)$ trend in the same EOF used here for describing the ZW3 oscillating pattern, but over the period 1950-2003. Our analysis reveals the presence of an upward ZW3 index trend that is larger in magnitude than that found by YL08, even though its value only reaches the $95 \%$ SL (Table 2). As our ZW3 index is based on MWS data (Fig. 1d), its upward trend suggests the presence of more/consistent colder equatorward air fluxes in the eastern Atlantic, eastern Indian and eastern Ross-Amundsen sectors, that is, on the leading side of the three HPCs over the midlatitudes oceans observed in Fig. 2d, and consistent with the fixed locations proposed by MW to compile the ZW3 index. This scenario could also come from the deepening of the three LPCs in the midlatitudes observed in Fig. $2 d$ and consistent with the fixed locations used by R04 to describe the ZW3 index variability. We also note that our upward ZW3 index trend could indicate decreasingly warmer poleward air fluxes in the western Indian, western Pacific-western Ross, and eastern Bellingshausen-Antarctic Peninsula-western Atlantic sectors, that is, on the trailing side of the three HPCs in the midlatitudes locations used by MW (Fig. 2d).

Trends within the indices investigated present interesting seasonal differences. Consistent with the SAMI, which shows significant $(p<0.01)$ upward trends in March-May (MAM) and December-February (DJF), an upward and significant $(p<0.01)$ SAO index trend is found in DJF. An upward SAO index trend is also found in MAM, although its value stands at the $95 \%$ SL (Table 2). Consistent with these results, 
downward and robust trends for the SST index are found in MAM $(p<0.01)$ and DJF $(p<0.01)$, and a significant $(p<0.01)$ downward SAT index trend is also detected in DJF. Finally, no significant seasonal trends are found for the ZW3 index.

Trends on the seasonal scale presented above indicate that a major occurrence of colder than normal conditions characterized the sub-Antarctic in summer, and this statement is also consistent with the upward TSIC index trend detected in DJF, whose value stands at the $99 \%$ SL (Table 2). Conversely to this latter finding, PC12 found no significant summer trend, either in SIA or in SIE data. We also note that our DJF TSIC index trend differs from that calculated by S15 for the SIE in the SH since he found upward monthly SIE trends in December and February at $95 \%$ and $90 \%$ SLs respectively, also detecting an insignificant trend in January. S15 also calculated seasonal SIE trends finding upward values for the October-December (OND) and January-March (JFM) seasons at $99 \%$ and $90 \%$ SLs respectively. However, the upward SIE trends found by S15 suggest the presence of colder than normal conditions around Antarctica in late spring when, on the contrary, we detect an insignificant TSIC index trend (Table 2).

The upward and significant trends found for the SAMI and PSA index in MAM could indicate the permanence of protracted colder than normal conditions on Antarctica since the previous summers, and these factors also could influence the sea ice pack growth in the following autumn/winter season. These statements are consistent with the downward (upward) and significant SST index (SAO index) trend detected in MAM, and with the upward TSIC index trend also found in this season (Table 2), although the significance of this latter trend is low $(p<0.1)$. The upward MAM TSIC index trend is in partial agreement with findings of S15, who found more highly significant upward monthly SIE trends in March, April, and May, and on a seasonal scale in JFM and April-June (AMJ) (at 90\% and 99\% SLs respectively). Similarly, our finding is partially in agreement with that shown in PC12's analysis, who found upward SIA and SIE trends in autumn at $99 \%$ and 95\% SLs respectively.

\section{b. Spearman's rho test}

The SLs of trends discussed above are calculated also applying the Spearman's rho (SR) test (Lehmann 1975; Sneyers 1990; Hipel and McLeod 1994). This is a nonparametric rank-based statistical trend test that has a similar power to the MK test previously discussed. Although the capabilities of the SR and MK tests are indistinguishable in practice, these are widely used in
TABLE 3. Annual and seasonal linear trends (changes per decade) in standardized climate indices and TSIC, SAT, and SST indices series for the 32-yr period spanning from January 1982 to December 2013. The statistical significance of the trends is derived by the application of the Spearman's rho test and is indicated by the typeface: bold (99\%), bold italic (95\%), and italic (90\%).

\begin{tabular}{lrrrrr}
\hline \hline & \multicolumn{5}{c}{ Spearman's rho trend test } \\
\cline { 2 - 6 } & ANNUAL & \multicolumn{1}{c}{ MAM } & \multicolumn{1}{c}{ JJA } & \multicolumn{1}{c}{ SON } & \multicolumn{1}{c}{ DJF } \\
\hline SAMI & $\mathbf{0 . 1 7 2 2}$ & $\mathbf{0 . 2 4 4 4}$ & 0.1101 & 0.0075 & $\mathbf{0 . 3 2 1 4}$ \\
SAO index & $\mathbf{0 . 1 5 6 8}$ & 0.2105 & 0.0716 & -0.0905 & $\mathbf{0 . 4 3 1 0}$ \\
PSA index & $\mathbf{0 . 1 7 4 1}$ & $\mathbf{0 . 2 6 4 1}$ & 0.0924 & 0.0885 & 0.2461 \\
ZW3 index & $\mathbf{0 . 1 2 1 9}$ & 0.1820 & 0.1035 & 0.1087 & 0.0897 \\
SAT index & $\mathbf{0 . 1 3 3 3}$ & 0.1417 & $\mathbf{0 . 3 8 8 7}$ & $\mathbf{0 . 4 6 2 2}$ & $\mathbf{- 0 . 4 6 3 6}$ \\
SST index & $\mathbf{- 0 . 4 9 8 1}$ & $\mathbf{- 0 . 3 4 8 5}$ & $\mathbf{- 0 . 6 3 5 1}$ & $\mathbf{- 0 . 5 9 1 5}$ & $\mathbf{- 0 . 4 0 1 8}$ \\
TSIC index & $\mathbf{0 . 4 8 9 9}$ & 0.2850 & 0.4916 & $\mathbf{0 . 6 1 4 8}$ & $\mathbf{0 . 5 5 3 2}$ \\
\hline
\end{tabular}

combination for comparison purposes (Yue et al. 2002; Shadmani et al. 2012; Ahmad et al. 2015). Yue et al. (2002) observed that, as the sample size of time series increases, the two tests become more powerful; on the contrary, when the amount of variation increases within a time series, the power of these tests decreases. Since the variability in our data highlights strong seasonal differences, different confidence levels by the application of the two trend tests could be expected. Here, we will compare results of the two tests with the aim of strengthening the value of the statements postulated in section 6 a.

Table 3 illustrates the magnitude and the SL of SST, SAT, TSIC, and climate index trends on annual and seasonal scales calculated by the application of the SR test. According to previous MK test results the SST and TSIC indices show highly significant $(p<0.01)$ annual trends. Likewise, highly significant $(p<0.01)$ annual trends result for the SAMI, SAO index, and PSA index. Conversely to the MK test result, we note that the annual SAT index trend reaches the 95\% SL when analyzed through the SR test. Discrepancies are also observed comparing the SLs of seasonal trends. We note that the SAMI trend in MAM stands at the $95 \%$ SL, and the SAO index trend in MAM lacks an acceptable significance level ( $p<0.1$ ) (Table 3), both when examined with the SR test.

We note that the upward trends found in MAM for the SAMI (Tables 2 and 3 ) are consistent with the spatial distribution of MAM SLP trends calculated by S15 in the ERA-Interim reanalysis for the period 1979-2013. However, our upward MAM SAMI trends are more highly significant, both in the MK and SR tests, than that detected by $\mathrm{S} 15$ in this season. We observe that the strong zonal asymmetry in MAM SLP trends distribution shown in S15's analysis reflect the character of a PSA wave type or SAM-PSA combination. This feature 
is consistent with our upward PSA index trends found in MAM, whose significance $(p<0.05)$ is proven by the application of both trend tests adopted in this study (Tables 2 and 3). We also argue that the spatial structure of MAM SLP trends, shown in the analysis in S15, could reflect the annular spatial shape of the SAO, since the deepening of pressures that he estimated is consistent with the strong influence of the SAO pattern in the southwestern Pacific, south Indian Ocean, and the western Antarctic continent along the southeastern Pacific coast (YL08). This finding, on the other hand, reflects our upward SAO index trend estimated in MAM, which reaches the $95 \%$ SL in the MK test (Table 2).

As for the TSIC index, the September-November (SON) trend value reaches the $95 \%$ SL when it is examined through the SR test (Table 3). This finding broadens our perspective because it is indicative of the sea ice intensification (Holland 2014) during the Antarctic spring. In addition, this upward trend also reflects the presence of persisting colder than normal conditions in the sub-Antarctic lower troposphere, a feature that is highly consistent with the opening of the ozone hole recorded in spring (Thompson and Wallace 2000a,b; Son et al. 2008; Polvani et al. 2011). This scenario is also supported by the strong downward SST index trends detected in SON, whose values stand at the $99 \%$ level both in MK and in SR tests (Tables 2 and 3). We note that the upward SON TSIC index trend found here is in partial agreement with findings of PC12, who found an upward but insignificant trend in SIA and an upward trend, highly significant at $99 \%$ SL, in SIE, both in spring. On the contrary, our finding is consistent with the SIE trend calculated by S15 even though the significance of our SON TSIC index trend is lower $(p<0.05)$. Actually, he found upward monthly SIE trends in September, October and November, and upward seasonal SIE trends in July-September (JAS) and OND, both at 99\% SLs.

According to MK test results, the upward TSIC index trends in MAM and June-August (JJA) (Table 2) show equal SLs when these are examined with the SR test (Table 3). Conversely to findings of S15, who found upward and significant ( $p<0.05$ or less) monthly and seasonal SIE trends in June, July, and August, and in AMJ and JAS, our upward JJA TSIC index trend is a bit less significant $(p<0.1)$. Furthermore, our finding is in partial agreement with PC12's results, since they found upward and highly significant $(p<0.01)$ trends in SIA and SIE. However, the modulation of the JJA TSIC index trend could be related to more regional than hemispheric influences, since no interesting trends in climate modes are detected in this season.
The SR test also shows upward and highly significant $(p<0.01)$ trends in DJF for the SAMI, SAO index, and TSIC index (Table 3). The upward SAMI DJF trends are consistent both with the spatial distribution of DJF SLP trends and with the DJF SAM index trend calculated by S15, even though higher SLs $(p<0.01)$ are found here for the SAMI (Tables 2 and 3). In addition, the highly significant $(p<0.01)$ and upward DJF SAO index trends appear to be consistent with the deepening of the CPT (Tables 2 and 3).

In summary, the SR and MK tests detect very heterogeneous confidence levels for trends associated with the climate indices and SST, SAT, and TSIC indices, although their statistical significance is substantially found in agreement. Exceptions only regard the SL of the annual SAT index trend ( $p<0.1$ in the MK test; $p<$ 0.05 in the SR test), that of the MAM SAO index trend $(p<0.05$ in the MK test; $p<0.1$ in the SR test) and, finally, that of the SON TSIC index trend $(p<0.5$ in the MK test; $p<0.05$ in the SR test).

\section{Seasonality of climate modes and sea ice concentration}

While the SAM, SAO, PSA, and ZW3 patterns may be positive or negative at any time, there are preferred times of occurrence associated with the fact that the four climate modes have annual cycles. Here, to construct the annual cycle, we need to examine climate indices and total SIC time series that internally retain the seasonality. Therefore, monthly anomaly time series of SLP, T500, and Z500 are calculated by subtracting the 32-yr climatological annual means from the monthly mean data. Then, following Eqs. (1), (2), and (3) presented in section 3, the SAMI, SAO, and PSA indices (hereinafter SAMIclim, SAOclim index, and PSAclim index) are reconstructed respectively.

Monthly anomalies of MWS are also calculated by subtracting the 32-yr climatological annual means from the monthly mean values, and then the residual series are investigated with the EOF analysis. Here, the second EOF mode of monthly MWS anomalies is chosen to represent the time series of the ZW3 oscillating pattern (hereinafter ZW3clim index). This EOF is found to be strongly correlated with the leading EOF mode $(r=0.81, p<0.01)$ in deseasonalized monthly MWS anomalies previously discussed, highlighting their strong similarity.

Finally, monthly anomalies time series of SIC are calculated by subtracting the 32 -yr climatological annual means from the monthly mean concentration values. Then, monthly anomalies over all SH longitudes are averaged to compile a time series describing the total 

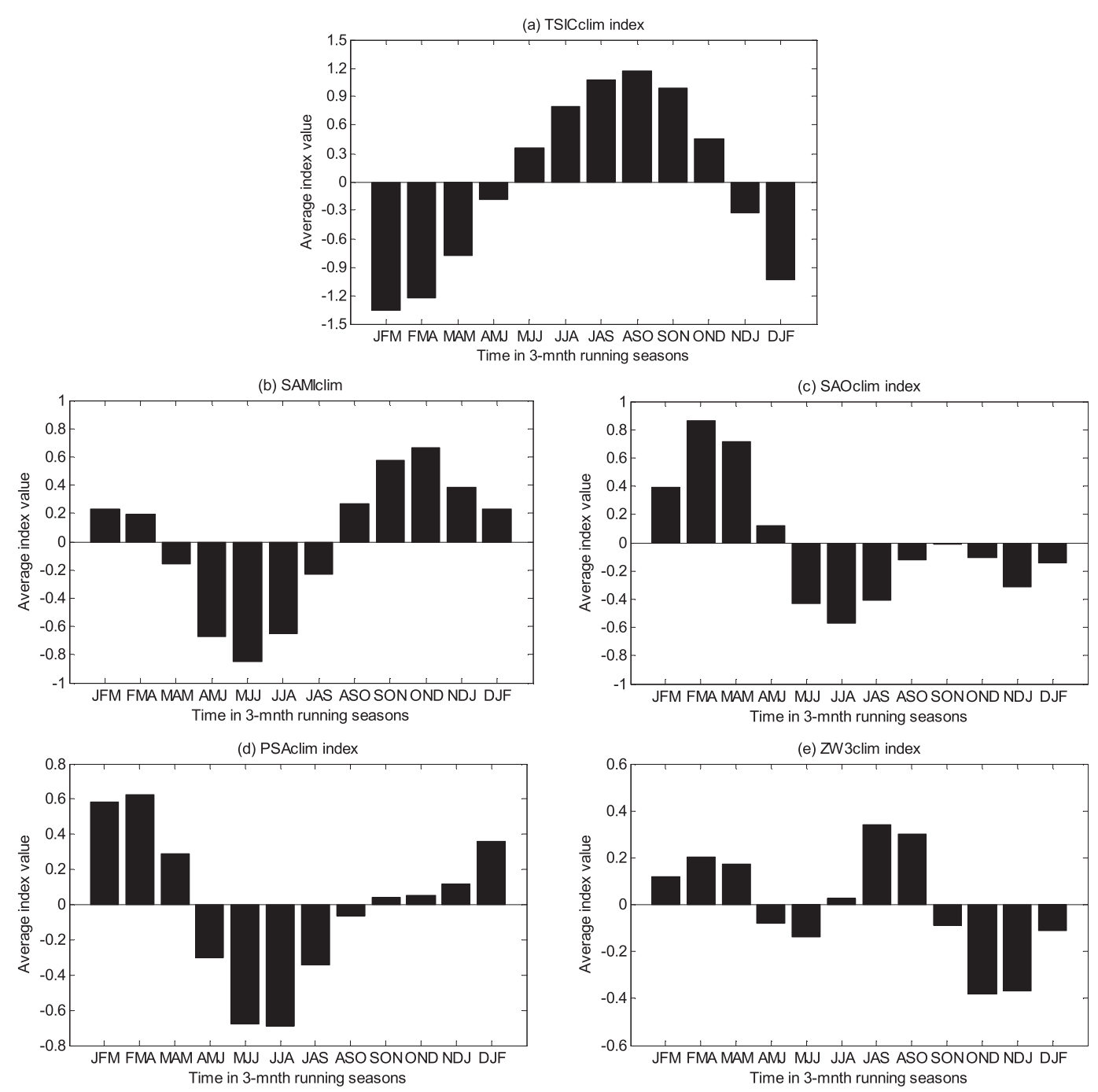

FIG. 9. The 3-month mean standardized anomalies of the (a) TSICclim index, (b) SAMIclim, (c) SAOclim index, (d) PSAclim index, and (e) ZW3clim index (see text) over the 32-yr period spanning from January 1982 to December 2013. Monthly anomalies are calculated by subtracting the 32 -yr annual mean from monthly mean data. The $x$ axis is time in 3-month running means and the $y$ axis is the average of amplitudes.

SIC variations around Antarctica (hereinafter TSICclim index). Anomalies averaged are those that satisfy conditions explained in section 3 as done for constructing the TSIC index based on deseasonalized monthly anomalies.

Before calculating the annual cycle, the monthly anomaly time series are aggregated into 3-month running mean seasons. The benefits arising from this procedure are discussed in section 4 . The annual cycle of climate indices and TSICclim index (Fig. 9) show the occurrence of anomaly phases during seasons. We argue that the comparison between the annual cycle of each climate index and that associated with the TSICclim index allows more directly detecting the climate patternssea ice relationships.
The TSICclim index (Fig. 9a) shows positive values from AMJ to OND and negative values from early summer [November-January (NDJ)] to MAM. In particular, a maximum positive value is observed during early spring [August-October (ASO)], and a maximum negative value is reached in JFM. The annual cycle illustrates the slow advance of the sea ice platform during months of growth and the fast retreat during the months of melt, as a rapid shift from positive to negative values is observed. These variations are the result of key physical and thermodynamic processes related to the twice-yearly cycle of SAO, which influences the SIE behavior favoring its slow (fast) advance (retreat) in fall (in spring) (Enomoto and Ohmura 1990). 
The SAMIclim (Fig. 9b) presents negative values from MAM to JAS and positive values from ASO to early autumn [February-April (FMA)], and it is more intense in OND and early winter [May-July (MJJ)]. Similarly, the PSAclim index (Fig. 9d) shows positive values from SON to MAM, with a positive maximum in FMA, and negative values from AMJ to ASO, with the strongest minimum in JJA. We note that the SAMIclim and PSAclim index show more frequently negative phases from AMJ to JAS (Figs. 9b,d). On the contrary, a positive SAMIclim-PSAclim index relationship (Figs. 9b,d) is more frequently observed from SON to FMA (i.e., when the sea ice melting occurs) (Fig. 9a).

The SAOclim index (Fig. 9c) shows positive values from JFM to AMJ and negative values from MJJ to DJF, and it is most strongly positive in FMA and strongly negative in JJA, when the PSAclim index exhibits the strongest values (Figs. 9c,d). Note that the annual cycle of SAOclim index exhibits a once-yearly oscillation (Fig. 9c). This feature reflects the weakening of the SAO signal as it does not show the second positive halfoscillation in spring, in agreement with results proposed in early studies (van Loon et al. 1993; Hurrell and van Loon 1994). Later, van den Broeke (2000a,b) also suggested that the observed weakening of SAO signal since the late 1970s and the increased storminess during solstitial months have had a direct impact on the timing of sea ice advance and retreat.

The ZW3clim index is characterized by a strong twiceyearly oscillation (Fig. 9e). It shows negative values from SON to DJF and from AMJ to MJJ, whereas positive index values are observed from JFM to MAM and from JJA to ASO. This ZW3 cycle is in partial agreement with van Loon and Jenne's (1972) analysis, who detected a maximum for the ZW3 pattern in winter and a second, smaller maximum in summer. The rapid shift from positive to negative phase indicates that the asymmetry of the ZW3 pattern has strong summer/ autumn and winter/spring differences (Fig. 9e). In winter the ZW3clim index is largely positive, indicating the presence of more meridional flows whereas in spring it shows negative values, suggesting the dominance of a more zonally oriented flow (R04). These features occur in association with negative (positive) winter (spring) values of the SAMI (Fig. 9b), which indicate the weakening (strengthening) of the zonal flow. The ZW3clim index shows more frequently negative oscillations from AMJ to MJJ, as the PSA index does in the last three decades (Figs. 9d,e).

From JJA to ASO, the phase inversion of the ZW3 pattern (from negative to positive phase) in the midlatitudes (Fig. 9e) is accompanied by important changes in the associated meridional flows. These flows influence
TABLE 4. Annual linear trends for separated decades 1982-91, 1992-2001 and 2002-11 in standardized climate indices and TSIC, SAT, and SST indices time series. The statistical significance of the trends is derived by the application of the Mann-Kendall test modified to account for autocorrelation on the time series (Hamed and Rao 1998; Blain 2013), and is indicated by the typeface: bold (99\%), bold italic (95\%), and italic (90\%).

\begin{tabular}{lrrr}
\hline \hline & \multicolumn{3}{c}{ Mann-Kendall trend test } \\
\cline { 2 - 4 } & $1982-91$ & $1992-2001$ & $2002-11$ \\
\hline SAMI & -0.0505 & $\mathbf{0 . 7 7 6 7}$ & $\mathbf{0 . 7 7 2 1}$ \\
SAO index & -0.3203 & $\mathbf{0 . 7 1 6 9}$ & $\mathbf{0 . 8 4 4 1}$ \\
PSA index & 0.1521 & $\mathbf{1 . 3 1 9 6}$ & $\mathbf{0 . 8 8 0 0}$ \\
ZW3 index & -0.0801 & $\mathbf{0 . 6 2 7 8}$ & $\mathbf{0 . 5 6 0 0}$ \\
SAT index & 0.2456 & -0.0601 & $\mathbf{- 0 . 2 6 0 5}$ \\
SST index & 0.0798 & $\mathbf{- 0 . 5 3 7 2}$ & $\mathbf{- 0 . 9 8 4 2}$ \\
TSIC index & -0.3122 & -0.1436 & $\mathbf{2 . 6 6 7 9}$ \\
\hline
\end{tabular}

the external edge of the regional sea ice coverages because in these months the total SIC reaches its maximum (Fig. 9a). On the contrary, in SON and even more in the following seasons, the phase inversion of the ZW3 pattern (from positive to negative phase) is observed in association with the total SIC retreat (cf. Figs. 9a and 9e). This indicates that the meridional flows associated with the ZW3 negative phase influence the time of melting of sea ice coverages in regional sectors where, in the previous months, their growth has been influenced by the ZW3 pattern in positive phase. In this context, the SAM pattern has a strong role since the SAMIclim (Fig. 9b) reaches its positive maximum in these seasons, thus indicating the presence of stronger zonal flows in the sub-Antarctic. On the contrary, the PSA pattern has a secondary role as it exhibits very low and slightly positive magnitudes (Fig. 9d).

\section{Decadal variations of trends in climate modes and sea ice concentration}

We present results of trend analyses applied to SST, SAT, TSIC, and climate modes time series, whose trend values are calculated over separate decades (i.e., 1982 91, 1992-2001, and 2002-11). In this investigation we make use of deseasonalized and standardized monthly anomaly time series, as outlined in section 6 . Here, the SLs of decadal trends are calculated through the application of the MK trend test modified to account for autocorrelation on the time series (Hamed and Rao 1998; Blain 2013) and results are shown in Table 4. The evaluation of decadal trends allows to detect and quantify the main low-frequency variations occurred in the SH circulation during the studied period.

All the indices show quite heterogeneous trends during decade 1982-91. In detail, the SAMI and SAO 
index show downward and insignificant trends as those associated with the TSIC and ZW3 indices (Table 4). As for the PSA, SST, and SAT indices, these show upward but insignificant trends. A general and more consistent change in the $\mathrm{SH}$ circulation is observed in the decade 1992-2001, when the climate indices move on positive values, thus showing upward trends. We note that upward and significant $(p<0.01)$ trends are detected for the ZW3 and PSA indices, while upward but less significant $(p<0.05)$ trends are observed for the SAMI and SAO index (Table 4).

From the decade 1982-91 to the decade 1992-2001, the PSA index increases by 1.17 standard deviations (SD), the SAO index by $1.04 \mathrm{SD}$, the SAMI by $0.83 \mathrm{SD}$ and, finally, the ZW3 index by 0.71 SD. Although these values cannot be compared as the climate indices have different physical units, they indicate how large is the rate of change, observed in terms of magnitude of trends, from one decade to the next. Conversely to the increased climate indices trend values, a downward and insignificant trend is detected for the SAT and TSIC indices in the decade 1992-2001. We note that a slight recovery of $0.17 \mathrm{SD}$ is observed in the TSIC trend value against that found in the previous decade (Table 4), thus indicating the total sea ice intensification since the early 1990s. Consistently with this finding, in the decade 19922001 a strong and highly significant $(p<0.01)$ downward SST index trend is observed, and its value is 0.46 SD lower than that calculated for the previous decade, thus suggesting that colder than normal conditions are established in the seas surrounding Antarctica. We also note that a downward but insignificant trend characterizes the SAT index in decade 1992-2001. Actually, its value is $0.18 \mathrm{SD}$ lower than that observed in decade 1982-91, thus suggesting the beginning of a colder climate phase.

Stronger and more important variations are observed in the decade 2002-11, when all climate indices show upward and significant trend values, at $95 \%$ SL for the SAMI and SAO index and at 99\% SL for the PSA and ZW3 indices. Conversely to the SAO index trend detected in decade 2002-11, whose value is 0.13 SD larger than that observed in the previous decade, a slight reduction of trend values associated with the remaining climate patterns is observed in this decade (Table 4). While the decrease of the SAMI and ZW3 index trend values is negligible, the value of the PSA index trend is 0.44 SD lower than that detected in the previous decade. We note that the TSIC index exhibits a strong upward and significant $(p<0.01)$ trend during 2002-11, and its value is $2.81 \mathrm{SD}$ larger than that shown in the previous decade (Table 4). Consistent with this finding, downward and significant $(p<0.01)$ SST and SAT indices trends are detected in this decade. We also note that the 2002-11 trend value associated with the SAT index is $0.20 \mathrm{SD}$ smaller than that observed in previous decade. Likewise, the SST trend value calculated in this decade is $0.45 \mathrm{SD}$ smaller than that shown in the previous decade. These findings confirm the presence of colder than normal conditions in the sub-Antarctic.

We argue that impacts from the climate patterns more frequently observed in positive phases during decades 1992-2001 and 2002-11 could have determined the unexpected sea ice intensification around Antarctica. In particular, we believe that the impacts from the PSA and ZW3 modes have had a leading role as, among the four climate patterns, these two patterns have shown the highest significant trends in the last two decades. This statement is also consistent with analysis results presented by Cerrone et al. (2017a), who found that the largest variance of the Antarctic SIC is concentrated on the quasi-triennial scale and comes from the impact of a PSA-ZW3 coupled wave (with the two patterns in phase) operating over the period 1982-2013.

\section{Decadal changes in seasonal cycle of climate modes}

In this section, the annual cycle of each climate index is constructed for separate decades (i.e., 1982-91, 19922001, and 2002-11). The aim of this application is to reveal how the occurrence of climate patterns is changed over time, from one decade to the next. Here we make use of standardized monthly anomaly time series of climate indices presented in section 6 , and results are shown in Figs. 10 and 11.

The SAMIclim shows a twice-yearly cycle in decade 1982-91 (Fig. 10a), but a once-yearly cycle is observed in decades 1992-2001 and 2002-11 (Figs. 10b,c). Actually, it is most strongly negative in MJJ, showing a progressive magnitude reduction over time in this season, and most strongly positive in SON in decade 1982-91 (Fig. 10a), presenting an onward shift of the positive maximum from SON to OND in the last two decades (Figs. 10b,c). We note that the SAMIclim is negative in DJF during decade 1982-91 (Fig. 10a), but it moves toward positive phases in the last two decades (Figs. 10b,c). This picture of variations is consistent with findings of Ding et al. (2012), who related the interdecadal changes of SAM since 1979 to a long-term trend in the tropical Pacific SSTs, arguing that the strong cooling experienced by the central Pacific SSTs has played a leading role in affecting the SAM downward trend during JJA from 1980s to 1990s. They also connected the strong cooling of the SSTs in the eastern Pacific sector during 

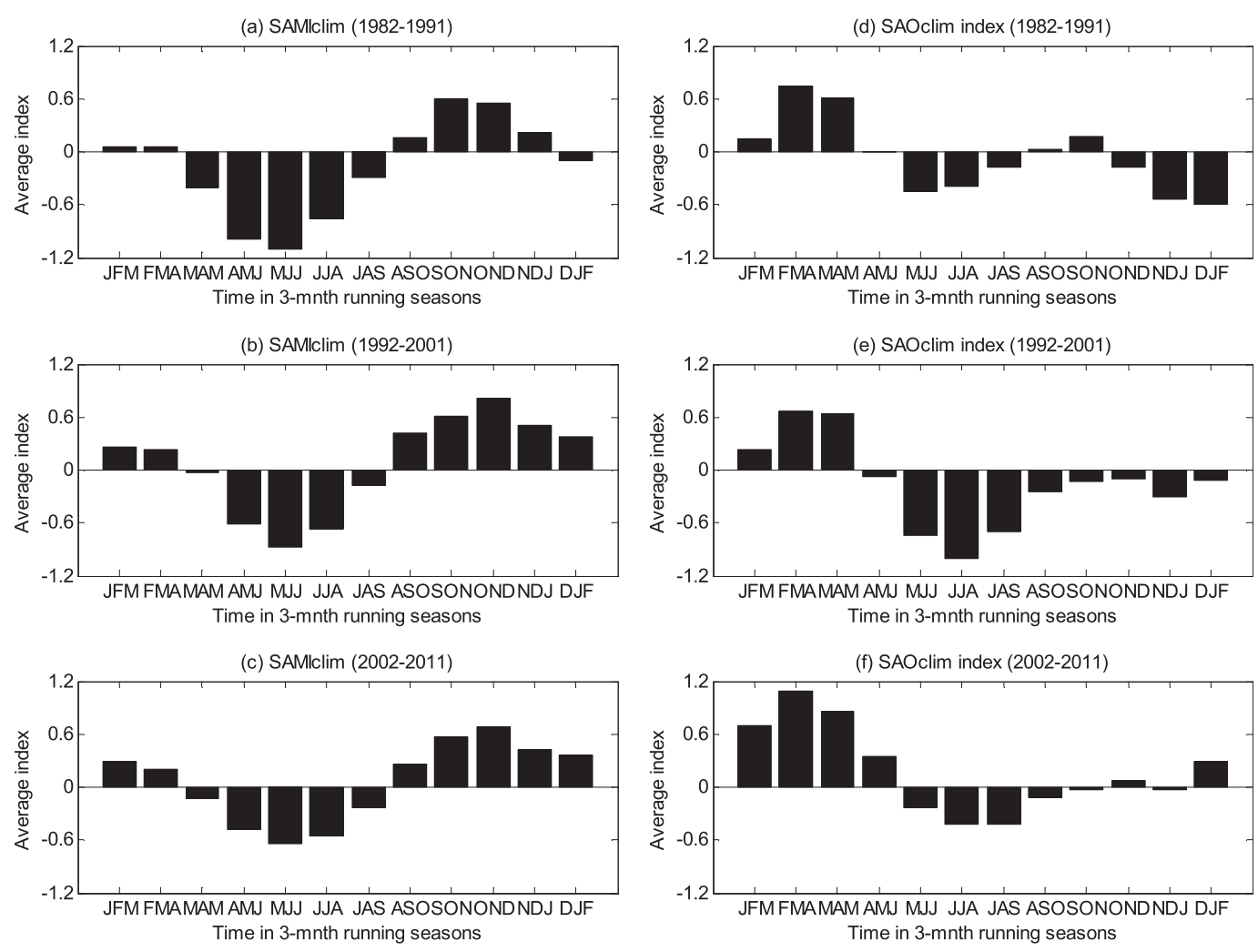

FIG. 10. (left) The 3-month mean standardized anomalies of the SAMIclim over the periods (a) 1982-91, (b) 1992-2001, and (c) 2002-11. (right) The 3-month mean standardized anomalies of the SAOclim index over the periods (d) 1982-91, (e) 1992-2001, and (f) 2002-11. Monthly anomalies are calculated by subtracting the 32-yr annual mean from monthly mean data. The $x$ axis is time in 3-month running means and the $y$ axis is the average of amplitudes.

the middle 1990s to the upward trend observed in the SAM during DJF.

We note that, from MJJ to JAS, the occurrence of negative SAMIclim values (Figs. 10a-c) is found in association with positive TSICclim index values (Fig. 9a). This feature suggests that more frequently negative SAM phases, which induce more meridional than zonal air flows in the sub-Antarctic, have influenced the growth of the total SIC in the last three decades. On the contrary, from ASO to OND, the occurrence of positive SAMIclim phases (Figs. 10a-c) is found in correspondence of positive TSICclim index values (Fig. 9a), indicating that more frequently positive SAM phases, which are associated with the presence of more zonal than meridional air flows in the sub-Antarctic, have determined the progressive insulation of Antarctica from the warmer midlatitudes, also retarding the sea ice melting in spring.

The SAOclim index exhibits a twice-yearly cycle in 1982-91 and 2002-11 (Figs. 10d,f) and only a onceyearly cycle in 1992-2001 (Fig. 10e). Overall, the studied period indicates that the SAOclim index is most strongly positive in FMA showing the strongest magnitudes during 2002-11 (Fig. 10f), the strongest negative DJF values in 1982-91 (Fig. 10d), and the strongest negative JJA values in the last two decades (Figs. 10e,f).

Since early 1990s, the fall phase of the SAO oscillation appears delayed into JJA, showing the strongest negative values in decade 1992-2001 (Fig. 10e), whereas the positive phase of the half-yearly SAO cycle in spring moves from SON in decade 1982-91 (Fig. 10d) to OND in decade 2002-11 (Fig. 10f) crossing the decade 1992-2001, where no positive spring values are detected (Fig. 10e). Similar results are described in van den Broeke's (1998a,b) analysis, who showed that since the mid to late 1970s, the spring SAO phase has delayed into November, probably due to the increase of the SSTs in the tropical eastern Pacific, a feature also connected to the presence of more frequent El Niño events. We argue that the decade 19922001 (Fig. 10e), when more negative spring SAO phases are observed, clearly reflects the weakening of the thermal gradient between the middle and high latitudes.

We also note that in 1982-91 (Fig. 10d) the spring negative SAO phases start in OND and protracts until 
(a) PSAclim index (1982-1991)

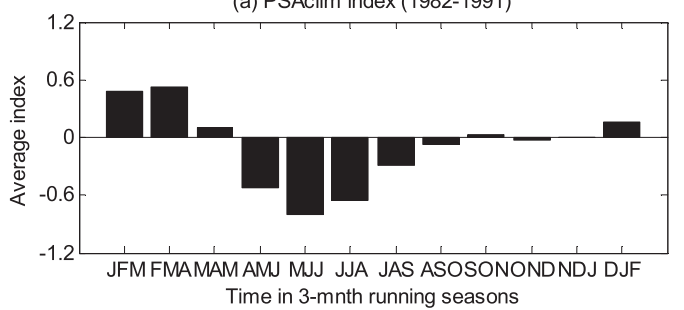

(b) PSAclim index (1992-2001)

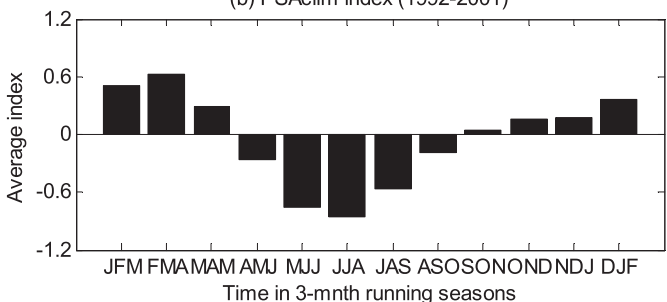

(c) PSAclim index (2002-2011)

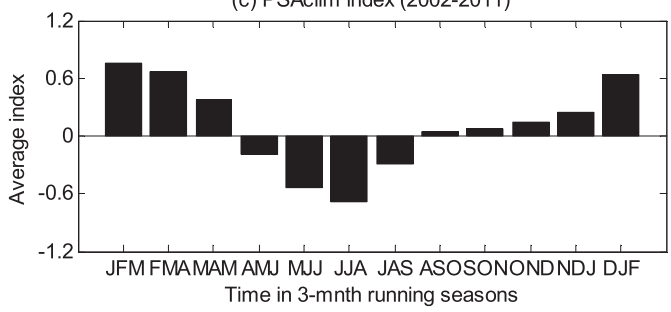

(d) ZW3clim index (1982-1991)

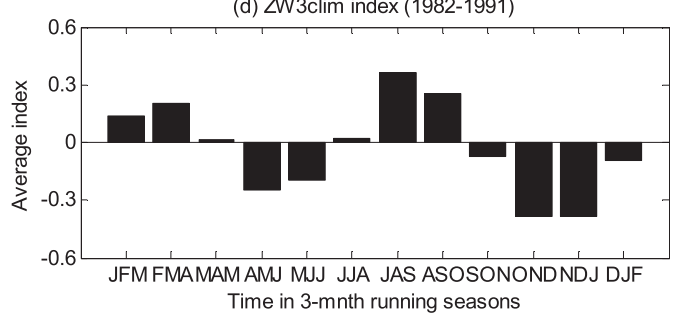

(e) ZW3clim index (1992-2001)

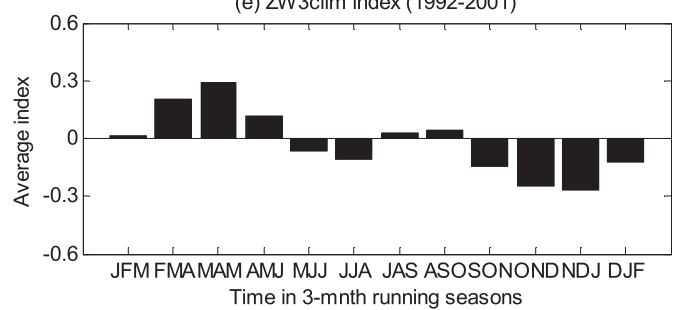

(f) ZW3clim index (2002-2011)

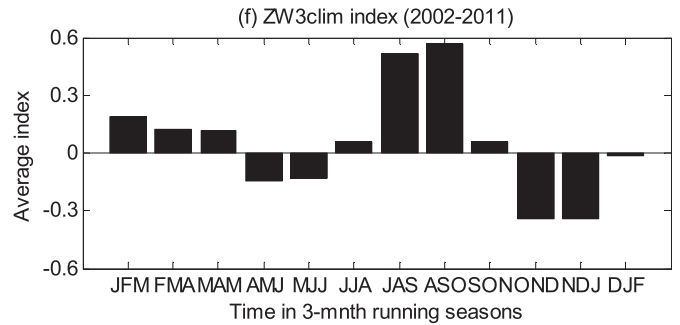

FIG. 11. As in Fig. 10, but for the PSAclim index.

DJF. On the contrary, in 2002-11 (Fig. 10f) the spring negative SAO phases appear weaker and are observed only in NDJ since positive conditions are immediately restored in DJF, persisting in the following months. These variations indicate that the positive SAO phases in fall start very soon (Fig. 10f) in 2002-11 (i.e., since the previous summer). These findings indicate the presence of a strong thermal gradient between the middle and high latitudes in the last decade, reflecting colder than normal conditions in the sub-Antarctic in the ice melting seasons. We also note that during 1982-91 negative SAO phases are observed from MJJ to JAS (Fig. 10d), whereas during 2002-11 these negative phases go on until SON (Fig. 10f). These features partially explain the interdecadal changes shown by the sea ice as, for example, the speed and time of growth and melting during solstitial months.

The PSAclim index shows the strongest negative values in MJJ in 1982-91 (Fig. 11a), presenting an onward shift of maximum in the last two decades (i.e., when the index is most strongly negative in JJA; Figs. 11b,c). On the contrary, the index appears most strongly positive in FMA in the first two decades (Figs. 11a,b), exhibiting a backward shift of its maximum in the last decade (i.e., when it is most strongly positive in JFM; Fig. 11c).
In the decade 1982-91, the PSAclim index shows a twice-yearly cycle with a first positive peak in FMA, and a second weaker positive peak in SON (Fig. 11a). We also note that the index reaches the strongest negative maximum in JJA in 1992-2001 (Fig. 11b) and the strongest positive maximum in JFM in 2002-11 (Fig. 11c). Furthermore, the index shows increasing magnitudes in DJF from one decade to the next (Figs. 11a-c). These findings suggest that negative PSA phases (El Niño conditions), especially from MJJ to JAS (Figs. 11a-c), have strongly influenced the sea ice growth since positive SIC anomalies are observed in these seasons (Fig. 9a). The opposite occurs in the melting seasons, especially from DJF to MAM, when positive PSA phases are more frequently observed in association with negative SIC anomalies (cf. Figs. 11a-c and 9a).

The ZW3clim index shows a twice-yearly cycle in the last three decades (Figs. 11d-f). It is most strongly positive in JAS in decade 1982-1991 (Fig. 11d), in MAM in 1992-2001 (Fig. 11e), and in ASO in 2002-2011 (Fig. 11f). On the contrary, the index shows most strongly negative values in NDJ in all three decades (Figs. 11d-f).

The positive ZW3 phases in fall appear longer in 1992-2001, as the ZW3clim index is most positive from 
JFM to AMJ (Fig. 11e). On the contrary, the negative ZW3 phases in fall start in AMJ in the decades 1982-91 and 2002-11 (Figs. 11d,f), showing an onward shift in 1992-2001, when the index is most negative since MJJ (Fig. 11e). This indicates that negative ZW3 phases have (in part) played a role in conditioning the sea ice growth during the decades 1982-91 and 2002-11.

The positive ZW3 phases observed in the second part of the year appear longer in decades 1982-91 and 200211 , since the ZW3clim index is most positive from JJA to ASO, and from JJA to SON, in the two decades respectively (Figs. 11d,f). Opposite conditions prevail in the decade 1992-2001, when the index is positive only from JAS to ASO (Fig. 11e).

The longest and strongest positive ZW3 phases detected from JJA to SON in the last decade (Fig. 11f) could have played an important role in influencing the external edge of the sea ice pack, since the SIC reaches its maximum in these seasons (Fig. 9a).

The ZW3clim index shows an anomalous annual cycle in the decade 1992-2001 (Fig. 11e). This feature was also observed by R04, who argued that positive phases have dominated the ZW3 pattern in 1990s, with the exception of a large negative excursion recorded in 1995-96. Probably, the low magnitudes shown by the ZW3 annual cycle in this decade (Fig. 11e) reflect the strongest variability of the mid-1990s. R04 also observed that the ZW3 index moves from strong positive to negative phases during several ENSO events, also indicating the co-occurrence between the large fluctuations of the index and those associated with the tropical SST. The PSA and ZW3 annual cycle behavior seems to support R04's statements since from SON to DJF, when the influences of ENSO extends over the SO, these patterns more frequently show opposite phases (cf. Figs. 11a-c and 11d-f).

\section{Temporal variations of climate modes and sea ice concentration}

To investigate variations occurring in the climate patterns and SIC around Antarctica, time series of deseasonalized and standardized monthly anomalies of total SIC and climate indices, based upon 3-month running mean, are collectively constructed and results are shown in Fig. 12.

The total SIC shows dominant negative values from the early 1980s to the mid-2000s, with the exception of brief positive excursions detected in 1994-96, 2000-01, and 2003-04 (Fig. 12a). On the contrary, negative SIC phases are observed during 1983-84, 1986-93, 1997-99, 2001-02, and 2005-06. We note that the SIC experiences a strong increase since early 2007 , a feature that appears consistent with the positive trends shown by climate indices. Actually, the amplitudes of these modes show large variations especially since the mid to late 2000s. In detail, the SAO index is most strongly positive since 2003 (Fig. 12c), and this feature is found in association with SAO trends previously discussed, and even more with the SAO trend value detected in the decade 2002 11 (Table 4). Similarly, the SAMI shows most strongly positive values since 2008 onward (Fig. 12b) in association with more frequent positive PSA and ZW3 phases (Figs. 12d,e), and all these variations appear to be consistent with the trends displayed in Table 4.

We believe that the coexistence of positive phases more frequently associated with these patterns could have strongly influenced the total SIC, which, as above observed, shows a sharp intensification in the last decade. In detail, the increase of positive SAM and SAO phases could have favored the progressive cooling of the sub-Antarctic. In contrast, the upward SAM trend could have reduced the SIC in the Bellingshausen and western Antarctic Peninsula sectors, where strong negative sea ice trends are recorded. Similar consequences could come from the impact of PSA and ZW3 patterns, more frequently observed in positive phase, which negatively affect the sea ice coverages in these two locations.

\section{Summary and conclusions}

In this paper the NCEP-NCAR composite dataset is used for compiling the climate indices describing the most important physical modes of variability in the $\mathrm{SH}$, known as the SAM, SAO, PSA, and ZW3 patterns. The impacts from these climate modes on the total Antarctic SIC, SST, and SAT signals in the sub-Antarctic are examined to detect the main variations affecting the climate mode-sea ice relationships on time scales ranging from seasonal to interdecadal over the 32-yr period (monthly means spanning from January 1982 to December 2013).

The covariability associated with the climate patterns is examined through correlation and spectral analyses.

Long-term linear trends in the SST, SAT, and SIC signals and climate indices are also detected and quantified by making use of two rank-based nonparametric statistical trend tests- the MK test modified to account for autocorrelation on the time series (Hamed and Rao 1998; Blain 2013) and the SR test-to reveal the extent of the climate change affecting the sub-Antarctic on time scales ranging from seasonal to interdecadal. These two trend tests are more suitable for detecting trends in climate time series, which are usually skewed and may be contaminated with outliers (Hirsch et al. 1982). 

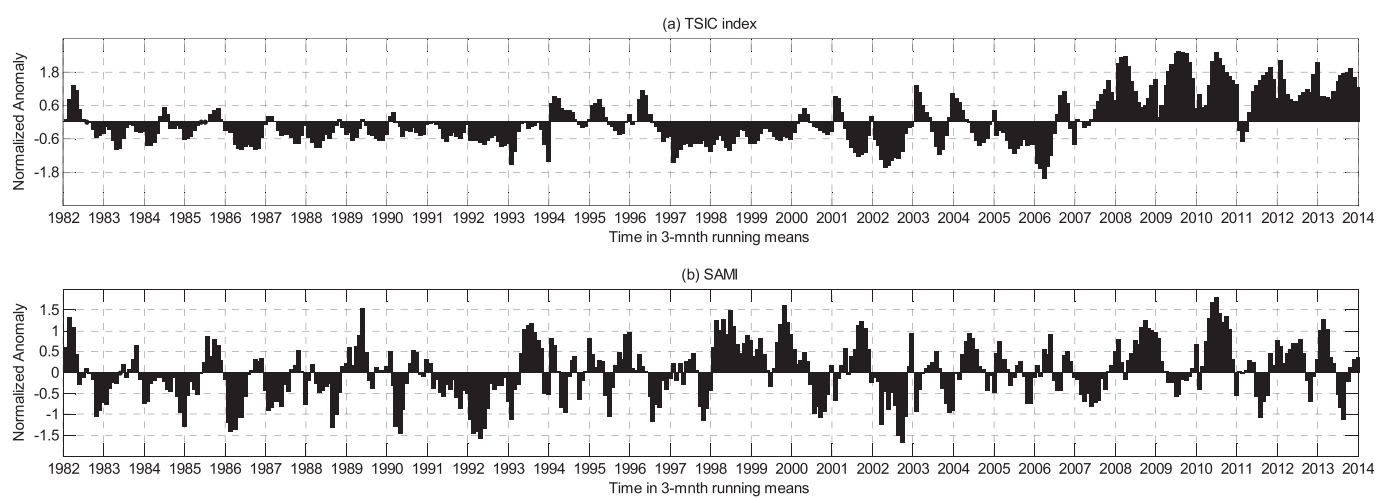

(c) SAO index

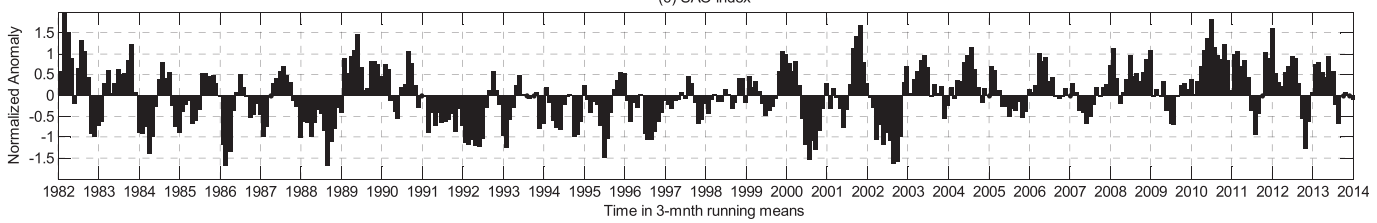

(d) PSA index

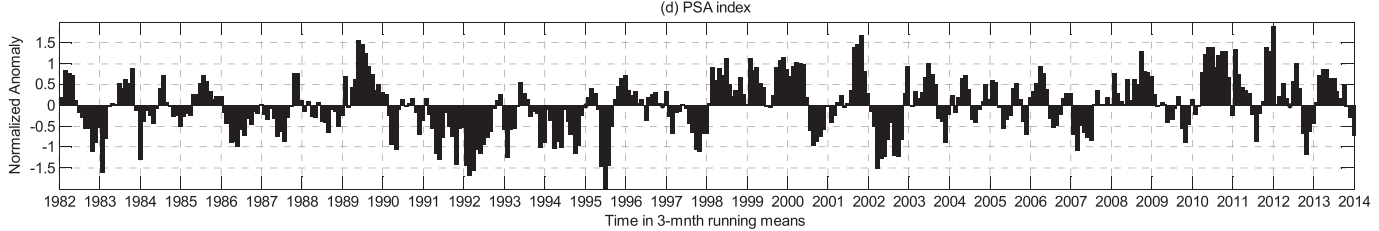

(e) ZW3 index

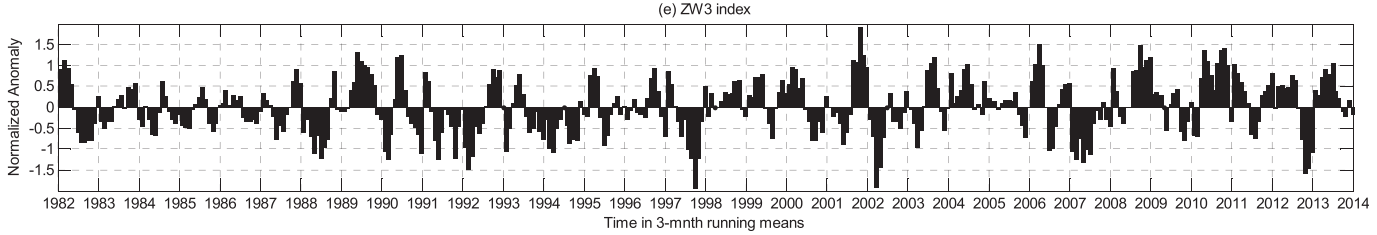

FIG. 12. Amplitudes of the (a) TSIC index, (b) SAMI, (c) SAO index, (d) PSA index, and (e) ZW3 index. Monthly anomalies are first deseasonalized and standardized, and then are aggregated in 3-month running means. This procedure suppresses the noise that might still be present at the monthly mean level and absorbs the spatial phase shifts of the climate modes and SIC. The net effect is a reduction in the size of time series during the time of movement, but little influence on their sign. Time series span the 32-yr period from January 1982 to December 2013. The $x$ axis is time in 3-month running means and the $y$ axis is the average of amplitudes.

The seasonality of climate patterns is also examined to better identify variations affecting the SO climate during the three decades investigated.

Results show that a progressive cooling characterized the year-to-year climate of the sub-Antarctic since 1990s. In detail, the cooling of the air-sea system surrounding Antarctica is found to be consistent with the impact from covariant positive SAM, SAO, and PSA phases on time scales ranging from 48 to 64 months. This colder scenario is also established during the 2000 decade, when the four climate patterns investigated show covariant positive phases on time scales ranging from 16 to 32 months (cf. Table 1 and Fig. 4). These findings are found to be consistent with increased positive SAM and SAO phases detected in terms of significant $(p<0.01$ or less) upward annual and seasonal trends (in MAM and
DJF; Tables 2 and 3$)$ and significant $(p<0.05)$ upward decadal trends (in decades 1992-2001 and 2002-11) (Table 4). The SIC reflects this picture of variations since it shows significant ( $p<0.01$ or less) upward annual and seasonal trends (in SON and DJF; Tables 2 and $3)$, also showing large intensifications in decade 19922001 , and a significant $(p<0.01)$ upward trend in decade 2002-11 (Table 4). Likewise, the SST signal shows significant $(p<0.01)$ downward annual and seasonal trends (in MAM, JJA, SON, and DJF; Tables 2 and 3), also showing significant $(p<0.01)$ decadal trends (in 1992-2001 and 2002-11; Table 4). On the contrary, the SAT signal only shows a significant $(p<0.01)$ downward DJF trend (Tables 2 and 3), large reductions during decade 1992-2001, and a significant $(p<0.01)$ downward trend in decade 2002-11 (Table 4). 
Findings discussed above are indicative of the progressive insulation of Antarctica from the warmer flows in the midlatitudes, which appear to be also consistent with variations observed in the PSA and ZW3 patterns. Actually, these two climate modes show significant ( $p<$ 0.01 or less) upward annual trends (Tables 2 and 3 ). Furthermore, we also detect a significant $(p<0.01)$ upward MAM trend for the PSA pattern (Tables 2 and $3)$ and significant $(p<0.01)$ upward decadal trends (in 1992-2001 and 2002-11) within the PSA and ZW3 modes (Table 4). The interpretation of our results also suggests the presence of a more frequent co-occurrence of the PSA and ZW3 patterns (with the two modes in phase) (Cerrone et al. 2017a) during the last decade (cf. Table 1, Table 4, and Fig. 4e).

These findings appear to be in contrast with those presented by Kohyama and Hartmann (2016), who find that a large amount of SIE variance is unexplained by linear relationships to ENSO and SAM, but it is rather explained by a Rossby wave-like mode. They also show that the statistical significance of the increasing sea ice trends on a regional scale disappears after regressing out the influence of ENSO or SAM, but conclude that these two modes are unable to explain the increasing trend of the hemispheric total SIE. Although our analyses are not regionally conducted but focus on the entire SO, these provide compelling evidences to believe that the superposition of climate variations discussed above and affecting the sub-Antarctic could explain, in part, the significant intensification of the regional and total Antarctic sea ice coverages.

The examination of seasonality associated with the climate patterns on the entire analyzed period (19822013) (Fig. 9) and on separate decades (1982-91, 19922001, 2002-11; Figs. 10 and 11) also suggests the guidelines to better interpret the air-sea ice interactions involved in the modulation of the climate mode-sea ice relationships presented above. A brief explanation of processes that could have favored the upward total SIC trends is given below.

In AMJ, negative SAM and PSA phases (Figs. 9b,d) induce meridional air fluxes that gradually cool the subAntarctic. This cooling occurs in association with the presence of positive SAO phases (Fig. 9c) and negative ZW3 phases (Fig. 9e), the first underlying the increased thermal gradient between the middle and high latitudes, and the second reflecting the presence of out-of-phase meridional atmospheric flows across the sub-Antarctic. These features appear strengthened when negative PSA phases lead the variability from AMJ to JAS (Fig. 9d). In JJA, negative SAM and PSA phases (Figs. 9b,d) persist and are accompanied by reversed SAO and ZW3 phases (positive phases) (Figs. 9c,e). The positive phase of the
ZW3 pattern in the midlatitudes induces meridional air fluxes oriented in opposite directions in comparison with those observed in the previous season.

In JAS and even more in ASO, the SAM moves on positive values (Fig. 9b) and promotes the intensification of westerlies, also insulating the Antarctic continent from the warmer atmospheric flows affecting the midlatitudes. Simultaneously, positive and strong ZW3 phases (Fig. 9e) affect the SIC completing the regional growth of sea ice coverage. In the following seasons the persistence of positive SAM phases in association with the increasingly presence of positive PSA phases until DJF limit the sea ice melting (Figs. 9b,d). In addition, the occurrence of negative ZW3 phases since SON (Fig. 9e), which indicates the presence of a more zonally oriented atmospheric flow (R04), favors the insulation of Antarctica from the warmer flows in the midlatitudes. As a consequence of this chain of events a slower than normal retreat of the sea ice coverage around Antarctica results from SON to DJF.

These variations could reflect the recent upward regional sea ice trends with the exception of the Bellingshausen and western Antarctic Peninsula sectors, where downward trends are recorded. Nonetheless, further studies are required for better understanding the impact of climate modes on the regional sea ice coverage.

Acknowledgments. This study was performed in the framework of Plankton Biodiversity and Functioning of the Ross Sea Ecosystems in a Changing Southern Ocean (P-ROSE) project as part of the Italian National Program for Research in Antarctica (PNRA). Data used in the study are provided by the NOAA/OAR/ESRL PSD, Boulder, Colorado, USA, from their Web site at http:// www.esrl.noaa.gov/psd/. The authors are grateful to Prof. Ian Simmonds for useful discussions and to the reviewers for helpful comments.

\section{REFERENCES}

Ackerley, D., and J. A. Renwick, 2010: The Southern Hemisphere semiannual oscillation and circulation variability during the mid-Holocene. Climate Past, 6, 415-430, https://doi.org/10.5194/ cp-6-415-2010.

Ahmad, I., D. Tang, T. Wang, M. Wang, and B. Wagan, 2015: Precipitation trends over time using Mann-Kendall and Spearman's rho tests in Swat River basin, Pakistan. $A d v$. Meteor., 2015, 431860, doi:10.1155/2015/431860.

Aulicino, G., G. Fusco, S. Kern, and G. Budillon, 2014: Estimation of sea-ice thickness in Ross and Weddell Seas from SSM/I brightness temperatures. IEEE Trans. Geosci. Remote Sens., 52, 4122-4140, https://doi.org/10.1109/TGRS.2013.2279799.

Blain, G. C., 2013: The modified Mann-Kendall test: On the performance of three variance correction approaches. Bragantia, 72, 416-425, https://doi.org/10.1590/brag.2013.045. 
Bracegirdle, T. J., and G. J. Marshall, 2012: The reliability of Antarctic tropospheric pressure and temperature in the latest global reanalyses. J. Climate, 25, 7138-7146, https://doi.org/ 10.1175/JCLI-D-11-00685.1.

Brahmananda Rao, V., A. M. C. do Carmo, and S. H. Franchito, 2003: Interannual variations of storm tracks in the Southern Hemisphere and their connections with the Antarctic Oscillation. Int. J. Climatol., 23, 1537-1545, https://doi.org/10.1002/ joc. 948 .

Carleton, A. M., 1988: Sea ice-atmosphere signal of the Southern Oscillation in the Weddell Sea, Antarctica. J. Climate, 1, 379-388, https://doi.org/10.1175/1520-0442(1988)001<0379: SISOTS $>2.0 . \mathrm{CO} ; 2$.

_- 1989: Antarctic sea-ice relationships with indices of the atmospheric circulation of the Southern Hemisphere. Climate Dyn., 3, 207-220, https://doi.org/10.1007/BF01058236.

Carvalho, L. M. V., C. Jones, and T. Ambrizzi, 2005: Opposite phases of the Antarctic Oscillation and relationships with intraseasonal to interannual activity in the tropics during the austral summer. J. Climate, 18, 702-718, https://doi.org/ 10.1175/JCLI-3284.1.

Cerrone, D., G. Fusco, I. Simmonds, G. Aulicino, and G. Budillon, 2017a: Dominant covarying climate signals in the Southern Ocean and Antarctic sea ice influence during the last three decades. J. Climate, 30, 3055-3072, https://doi.org/10.1175/ JCLI-D-16-0439.1.

,--1, Y. Cotroneo, I. Simmonds, and G. Budillon, 2017b: The Antarctic circumpolar wave: Its presence and interdecadal changes during the last 142 years. J. Climate, 30, 6371-6389, https://doi.org/10.1175/JCLI-D-16-0646.1.

Codron, F., 2005: Relation between annular modes and the mean state: Southern Hemisphere summer. J. Climate, 18, 320-330, https://doi.org/10.1175/JCLI-3255.1.

Cotroneo, Y., G. Budillon, G. Fusco, and G. Spezie, 2013: Cold core eddies and fronts of the Antarctic Circumpolar Current south of New Zealand from in situ and satellite data. J. Geophys. Res. Oceans, 118, 2653-2666, https://doi.org/ 10.1002/jgrc.20193.

Cox, D. R., and A. Stuart, 1955: Some quick sign tests for trend in location and dispersion. Biometrika, 42, 80-95, https://doi.org/ 10.1093/biomet/42.1-2.80.

Ding, Q., E. J. Steig, D. S. Battisti, and J. M. Wallace, 2012: Influence of the tropics on the southern annular mode. J. Climate, $\mathbf{2 5}$, 6330-6348, https://doi.org/10.1175/JCLI-D-11-00523.1.

Enomoto, H., and A. Ohmura, 1990: The influence of atmospheric half-yearly cycle on the sea ice extent in the Antarctic. J. Geophys. Res., 95, 9497-9511, https://doi.org/10.1029/ JC095iC06p09497.

Fusco, G., D. Flocco, G. Budillon, G. Spezie, and E. Zambianchi, 2002: Dynamics and variability of Terra Nova Bay polynya. Mar. Ecol., 23, 201-209, https://doi.org/10.1111/ j.1439-0485.2002.tb00019.x.

_ , G. Budillon, and G. Spezie, 2009: Surface heat fluxes and thermohaline variability in the Ross Sea and in Terra Nova Bay polynya. Cont. Shelf Res., 29, 1887-1895, https://doi.org/ 10.1016/j.csr.2009.07.006.

Garreaud, R. D., and D. S. Battisti, 1999: Interannual (ENSO) and interdecadal (ENSO-like) variability in the Southern Hemisphere tropospheric circulation. J. Climate, 12, 2113-2123, https:// doi.org/10.1175/1520-0442(1999)012<2113:IEAIEL>2.0.CO;2.

Gillett, N. P., T. D. Kell, and P. D. Jones, 2006: Regional climate impacts of the southern annular mode. Geophys. Res. Lett., 33, L23704, doi:10.1029/2006GL027721.
Gong, D., and S. Wang, 1999: Definition of the Antarctic Oscillation index. Geophys. Res. Lett., 26, 459-462, https://doi.org/ 10.1029/1999GL900003.

Hall, A., and M. Visbeck, 2002: Synchronous variability in the Southern Hemisphere atmosphere, sea ice, and ocean resulting from the annular mode. J. Climate, 15, 30433057, https://doi.org/10.1175/1520-0442(2002)015<3043: SVITSH $>2.0 . \mathrm{CO} ; 2$.

Hamed, K. H., and A. R. Rao, 1998: A modified Mann-Kendall trend test for autocorrelated data. J. Hydrol., 204, 182-196, https://doi.org/10.1016/S0022-1694(97)00125-X.

Hartmann, D. L., and F. Lo, 1998: Wave-driven zonal flow vacillation in the Southern Hemisphere. J. Atmos. Sci., 55, 1303-1315, https://doi.org/10.1175/1520-0469(1998)055<1303: WDZFVI $>2.0 . \mathrm{CO} ; 2$.

Hines, K. M., D. H. Bromwich, and G. J. Marshall, 2000: Artificial surface pressure trends in the NCEP-NCAR reanalysis over the Southern Ocean and Antarctica. J. Climate, 13, 3940-3952, https://doi.org/10.1175/1520-0442(2000)013<3940: ASPTIT $>2.0 . \mathrm{CO} ; 2$.

Hipel, K. W., and A. I. McLeod, 1994: Time Series Modelling of Water Resources and Environmental Systems. Developments in Water Science Series, Vol. 45, Elsevier, 1012 pp.

Hirsch, R. M., J. R. Slack, and R. A. Smith, 1982: Techniques of trend analysis for monthly water quality data. Water Resour. Res., 18, 107-121, https://doi.org/10.1029/WR018i001p00107.

Holland, M. M., C. M. Bitz, and E. C. Hunke, 2005: Mechanisms forcing an Antarctic dipole in simulated sea ice and surface ocean conditions. J. Climate, 18, 2052-2066, https://doi.org/ 10.1175/JCLI3396.1.

Holland, P. R., 2014: The seasonality of Antarctic sea ice trends. Geophys. Res. Lett., 41, 4230-4237, https://doi.org/10.1002/ 2014GL060172.

Hoskins, B. J., and D. J. Karoly, 1981: The steady linear response of a spherical atmosphere to thermal and orographic forcing. J. Atmos. Sci., 38, 1179-1196, https://doi.org/10.1175/ 1520-0469(1981)038<1179:TSLROA > 2.0.CO;2.

Hurrell, J. W., and H. van Loon, 1994: A modulation of the atmospheric annual cycle in the Southern Hemisphere. Tellus, 46A, 325-338, https://doi.org/10.3402/tellusa.v46i3.15482.

Irving, D., and I. Simmonds, 2015: A novel approach to diagnosing Southern Hemisphere planetary wave activity and its influence on regional climate variability. J. Climate, 28, 9041-9057, https://doi.org/10.1175/JCLI-D-15-0287.1.

Jones, J. M., and M. Widmann, 2004: Atmospheric science: Early peak in Antarctic Oscillation index. Nature, 432, 290-291, https://doi.org/10.1038/432290b.

Kalnay, E., and Coauthors, 1996: The NCEP/NCAR 40-Year Reanalysis Project. Bull. Amer. Meteor. Soc., 77, 437-471, https:// doi.org/10.1175/1520-0477(1996)077<0437:TNYRP>2.0.CO;2.

Karoly, D. J., 1989: Southern Hemisphere circulation features associated with El Niño-Southern Oscillation events. J. Climate, 2, 1239-1252, https://doi.org/10.1175/1520-0442(1989)002<1239: SHCFAW $>2.0 . \mathrm{CO} ; 2$.

1990: The role of transient eddies in low-frequency zonal variations of the Southern Hemisphere circulation. Tellus, 42A, 41-50, https://doi.org/10.3402/tellusa.v42i1.11858.

Kendall, M. G., 1955: Rank Correlation Methods. Griffin, 160 pp. , and A. Stuart, 1967: The Advanced Theory of Statistics. 2nd ed. Griffin, 690 pp.

Kidson, J. W., 1988a: Indices of the Southern Hemisphere zonal wind. J. Climate, 1, 183-194, https://doi.org/10.1175/ 1520-0442(1988)001<0183:IOTSHZ>2.0.CO;2. 
1988b: Interannual variations in the Southern Hemisphere circulation. J. Climate, 1, 1177-1198, https://doi.org/10.1175/ 1520-0442(1988)001<1177:IVITSH > 2.0.CO;2.

—, and M. R. Sinclair, 1995: The influence of persistent anomalies on Southern Hemisphere storm tracks. J. Climate, 8, 1938-1950, https://doi.org/10.1175/1520-0442(1995)008<1938: TIOPAO $>2.0 . \mathrm{CO} ; 2$

Kistler, R., and Coauthors, 2001: The NCEP-NCAR 50-Year Reanalysis: Monthly means CD-ROM and documentation. Bull. Amer. Meteor. Soc., 82, 247-267, https://doi.org/10.1175/ 1520-0477(2001)082<0247:TNNYRM > 2.3.CO;2.

Kohyama, T., and D. L. Hartmann, 2016: Antarctic sea ice response to weather and climate modes of variability. J. Climate, 29, 721-741, https://doi.org/10.1175/JCLI-D-15-0301.1.

Lefebvre, W., H. Goosse, R. Timmermann, and T. Fichefet, 2004: Influence of the southern annular mode on the sea ice-ocean system. J. Geophys. Res., 109, C09005, https://doi.org/10.1029/ 2004JC002403.

Lehmann, E. L., 1975: Nonparametrics: Statistical Methods Based on Ranks. Holden-Day, 457 pp.

Liu, J., X. Yuan, D. Rind, and D. G. Martinson, 2002: Mechanism study of the ENSO and southern high latitude climate teleconnections. Geophys. Res. Lett., 29, 1679, https://doi.org/ 10.1029/2002GL015143.

— J. A. Curry, and D. G. Martinson, 2004: Interpretation of recent Antarctic sea ice variability. Geophys. Res. Lett., 31, L02205, https://doi.org/10.1029/2003GL018732.

Lorenz, D. J., and D. L. Hartmann, 2001: Eddy-zonal flow feedback in the Southern Hemisphere. J. Atmos. Sci., 58, 33123327, https://doi.org/10.1175/1520-0469(2001)058<3312: EZFFIT > 2.0.CO;2.

Mann, H. B., 1945: Nonparametric tests against trend. Econometrica, 13, 245-259, https://doi.org/10.2307/1907187.

Marshall, G. J., 2002: Trends in Antarctic geopotential height and temperature: A comparison between radiosonde and NCEPNCAR reanalysis data. J. Climate, 15, 659-674, https://doi.org/ 10.1175/1520-0442(2002)015<0659:TIAGHA > 2.0.CO;2.

Meehl, G. A., 1991: A reexamination of the mechanism of the semiannual oscillation in the Southern Hemisphere. J. Climate, 4, 911-926, https://doi.org/10.1175/1520-0442(1991)004<0911: AROTMO $>2.0 . \mathrm{CO} ; 2$

Meneghini, B., I. Simmonds, and I. N. Smith, 2007: Association between Australian rainfall and the southern annular mode. Int. J. Climatol., 27, 109-121, https://doi.org/10.1002/joc.1370.

Mo, K. C., and H. van Loon, 1984: Some aspects of the interannual variation of mean monthly sea level pressure on the Southern Hemisphere. J. Geophys. Res., 89, 9541-9546, https://doi.org/ 10.1029/JD089iD06p09541.

—, and G. H. White, 1985: Teleconnections in the Southern Hemisphere. Mon. Wea. Rev., 113, 22-37, https://doi.org/ 10.1175/1520-0493(1985)113<0022:TITSH > 2.0.CO;2.

_ , and M. Ghil, 1987: Statistics and dynamics of persistent anomalies. J. Atmos. Sci., 44, 877-902, https://doi.org/10.1175/ 1520-0469(1987)044<0877:SADOPA > 2.0.CO;2.

— , and R. W. Higgins, 1998: The Pacific-South American modes and tropical convection during the Southern Hemisphere winter. Mon. Wea. Rev., 126, 1581-1596, https://doi.org/ 10.1175/1520-0493(1998)126<1581:TPSAMA > 2.0.CO;2.

— , and J. N. Paegle, 2001: The Pacific-South American modes and their downstream effects. Int. J. Climatol., 21, 1211-1229, https://doi.org/10.1002/joc.685.

Nan, S., and J. Li, 2003: The relationship between the summer precipitation in the Yangtze River valley and the boreal spring
Southern Hemisphere annular mode. Geophys. Res. Lett., 30, 2266, https://doi.org/10.1029/2003GL018381.

North, G. R., T. L. Bell, R. F. Cahalan, and F. J. Moeng, 1982: Sampling errors in the estimation of empirical orthogonal functions. Mon. Wea. Rev., 110, 699-706, https://doi.org/ 10.1175/1520-0493(1982)110<0699:SEITEO > 2.0.CO;2.

Parkinson, C. L., and D. J. Cavalieri, 2012: Antarctic sea ice variability and trends, 1979-2010. Cryosphere, 6, 871-880, https:// doi.org/10.5194/tc-6-871-2012.

Pezza, A. B., T. Durrant, I. Simmonds, and I. Smith, 2008: Southern Hemisphere synoptic behavior in extreme phases of SAM, ENSO, sea ice extent, and southern Australia rainfall. J. Climate, 21, 5566-5584, https://doi.org/10.1175/ 2008JCLI2128.1.

Polvani, L. M., D. W. Waugh, G. J. P. Correa, and S.-W. Son, 2011: Stratospheric ozone depletion: The main driver of twentiethcentury atmospheric circulation changes in the Southern Hemisphere. J. Climate, 24, 795-812, https://doi.org/10.1175/ 2010JCLI3772.1.

Raphael, M. N., 2001: Response of the large-scale, Southern Hemisphere extratropical atmospheric circulation to extremes of Antarctic sea-ice concentration in a general circulation model. Polar Geogr., 25, 218-238, https://doi.org/10.1080/ 10889370109377714

- 2004: A zonal wave 3 index for the Southern Hemisphere. Geophys. Res. Lett., 31, L23212, https://doi.org/10.1029/ 2004GL020365.

2007: The influence of atmospheric zonal wave three on Antarctic sea ice variability. J. Geophys. Res., 112, D12112, https://doi.org/10.1029/2006JD007852.

Rashid, H. A., and I. Simmonds, 2005: Southern Hemisphere annular mode variability and the role of optimal nonmodal growth. J. Atmos. Sci., 62, 1947-1961, https://doi.org/10.1175/ JAS3444.1.

Reason, C. J. C., 2000: Multidecadal climate variability in the subtropics/mid-latitudes of the Southern Hemisphere oceans. Tellus, 52A, 203-233, https://doi.org/10.3402/tellusa.v52i2.12259.

Reynolds, R. W., N. A. Rayner, T. M. Smith, D. C. Stokes, and W. Wang, 2002: An improved in situ and satellite SST analysis for climate. J. Climate, 15, 1609-1625, https://doi.org/10.1175/ 1520-0442(2002)015<1609:AIISAS > 2.0.CO;2.

Rogers, J. C., and H. van Loon, 1982: Spatial variability of sea level pressure and $500 \mathrm{mb}$ height anomalies over the Southern Hemisphere. Mon. Wea. Rev., 110, 1375-1392, https://doi.org/ 10.1175/1520-0493(1982)110<1375:SVOSLP $>2.0$.CO;2.

Rusciano, E., G. Budillon, G. Fusco, and G. Spezie, 2013: Evidence of atmosphere-sea ice-ocean coupling in the Terra Nova Bay polynya (Ross Sea-Antarctica). Cont. Shelf Res., 61-62, 112124, https://doi.org/10.1016/j.csr.2013.04.002.

Sen Gupta, A., and M. H. England, 2006: Coupled oceanatmosphere-ice response to variations in the southern annular mode. J. Climate, 19, 4457-4486, https://doi.org/10.1175/ JCLI3843.1.

Shadmani, M., S. Marofi, and M. Roknian, 2012: Trend analysis in reference evapotranspiration using Mann-Kendall and Spearman's rho tests in arid regions of Iran. Water Resour. Manage., 26, 211-224, https://doi.org/10.1007/s11269-011-9913-z.

Simmonds, I., 2015: Comparing and contrasting the behaviour of Arctic and Antarctic sea ice over the 35 year period 19792013. Ann. Glaciol., 56, 18-28, https://doi.org/10.3189/ 2015AoG69A909.

, and D. J. Walland, 1997: Decadal and centennial variability of the southern semiannual oscillation simulated in the GFDL 
coupled GCM. Climate Dyn., 14, 45-53, https://doi.org/ $10.1007 / \mathrm{s} 003820050207$.

_- and J. C. King, 2004: Global and hemispheric climate variations affecting the Southern Ocean. Antarct. Sci., 16, 401-413, https://doi.org/10.1017/S0954102004002226.

Sneyers, R., 1990: On the statistical analysis of series of observations. WMO Tech. Note 143, 192 pp.

Son, S.-W., and Coauthors, 2008: The impact of stratospheric ozone recovery on the Southern Hemisphere westerly jet. Science, 320, 1486-1489, https://doi.org/10.1126/science.1155939.

Szeredi, I., and D. J. Karoly, 1987: The horizontal structure of monthly fluctuations of the Southern Hemisphere troposphere from station data. Aust. Meteor. Mag., 35, 119-129, http:// www.bom.gov.au/jshess/docs/1987/szeredi2.pdf.

Tamura, T., K. I. Ohshima, T. Markus, D. J. Cavalieri, S. Nihashi, and N. Hirasawa, 2007: Estimation of thin ice thickness and detection of fast ice from SSM/I data in the Antarctic Ocean. J. Atmos. Oceanic Technol., 24, 1757-1772, https://doi.org/ 10.1175/JTECH2113.1.

Taschetto, A., I. Wainer, and M. Raphael, 2007: Interannual variability associated with semiannual oscillation in southern high latitudes. J. Geophys. Res., 112, D02106, https://doi.org/ 10.1029/2006JD007648

Thompson, D. W. J., and J. M. Wallace, 2000a: Annular modes in the extratropical circulation. Part I: Month-to-month variability. J. Climate, 13, 1000-1016, https://doi.org/10.1175/ 1520-0442(2000)013<1000:AMITEC > 2.0.CO;2.

— , and _ 2000b: Annular modes in the extratropical circulation. Part II: Trends. J. Climate, 13, 1018-1036, https:// doi.org/10.1175/1520-0442(2000)013<1018:AMITEC $>2.0 . C O ; 2$

— , and S. Solomon, 2002: Interpretation of recent Southern Hemisphere climate changes. Science, 296, 895-899, https:// doi.org/10.1126/science.1069270.

_- M. P. Baldwin, and J. M. Wallace, 2002: Stratospheric connection to Northern Hemisphere wintertime weather: Implications for prediction. J. Climate, 15, 1421-1428, https:// doi.org/10.1175/1520-0442(2002)015<1421:SCTNHW>2.0.CO;2.

Trenberth, K. E., 1980: Planetary waves at $500 \mathrm{mb}$ in the Southern Hemisphere. Mon. Wea. Rev., 108, 1378-1389, https://doi.org/ 10.1175/1520-0493(1980)108<1378:PWAMIT>2.0.CO;2.

—_, and K. C. Mo, 1985: Blocking in the Southern Hemisphere. Mon. Wea. Rev., 113, 3-21, https://doi.org/10.1175/ 1520-0493(1985)113<0003:BITSH > 2.0.CO;2.

Turner, J., S. A. Harangozo, G. J. Marshall, J. C. King, and S. R. Colwell, 2002: Anomalous atmospheric circulation over the Weddell Sea, Antarctica during the austral summer of 2001/02 resulting in extreme sea ice conditions. Geophys. Res. Lett., 29, 2160, https://doi.org/10.1029/2002GL015565.

,-- J. J. King, W. M. Connolley, T. A. Lachlan-Cope, and G. J. Marshall, 2003: An exceptional winter sea-ice retreat/ advance in the Bellingshausen Sea, Antarctica. Atmos.Ocean, 41, 171-185, https://doi.org/10.3137/ao.410205.

van den Broeke, M. R., 1998a: The semi-annual oscillation and Antarctic climate. Part 1: Influence on near surface temperatures
(1957-79). Antarct. Sci., 10, 175-183, https://doi.org/10.1017/ S0954102098000248.

1998b: The semi-annual oscillation and Antarctic climate.

Part 2: Recent changes. Antarct. Sci., 10, 184-191, https:// doi.org/10.1017/S095410209800025X.

_ 2000a: The semi-annual oscillation and Antarctic climate. Part 4: A note on sea ice cover in the Amundsen and Bellingshausen Seas. Int. J. Climatol., 20, 455-462, https://doi.org/10.1002/ (SICI)1097-0088(20000330)20:4<455::AID-JOC482>3.0.CO;2-M.

- 2000b: On the interpretation of Antarctic temperature trends. J. Climate, 13, 3885-3889, https://doi.org/10.1175/ 1520-0442(2000)013<3885:OTIOAT>2.0.CO;2.

van Loon, H., 1956: Blocking action in the Southern Hemisphere, Part I. Notos, 5, 171-177.

—, 1967: The half-yearly oscillations in middle and high southern latitudes and the coreless winter. J. Atmos. Sci., 24, 472-486, https://doi.org/10.1175/1520-0469(1967)024<0472: THYOIM $>2.0 . \mathrm{CO} ; 2$.

_ , and R. L. Jenne, 1972: The zonal harmonic standing waves in the Southern Hemisphere. J. Geophys. Res., 77, 992-1003, https://doi.org/10.1029/JC077i006p00992.

—, J. W. Kidson, and A. B. Mullan, 1993: Decadal variation of the annual cycle in the Australian dataset. J. Climate, 6, 1227-1231, https://doi.org/10.1175/1520-0442(1993)006<1227: DVOTAC $>2.0 . \mathrm{CO} ; 2$.

Van Woert, M. L., 1999: Wintertime dynamics of the Terra Nova Bay polynya. J. Geophys. Res., 104, 7753-7769, https://doi.org/ 10.1029/1999JC900003.

Venegas, S. A., 2003: The Antarctic Circumpolar Wave: A combination of two signals? J. Climate, 16, 2509-2525, https:// doi.org/10.1175/1520-0442(2003)016<2509:TACWAC >2.0.CO;2.

Wallace, J. M., and H.-H. Hsu, 1983: Ultra-long waves and two-dimensional Rossby waves. J. Atmos. Sci., 40, 22112219, https://doi.org/10.1175/1520-0469(1983)040<2211: ULWATD $>2.0 . \mathrm{CO} ; 2$.

Watkins, A. B., and I. Simmonds, 1999: A late sprint surge in the open water of the Antarctic sea pack. Geophys. Res. Lett., 26, 1481-1484, https://doi.org/10.1029/1999GL900292.

Yoden, S., M. Shiotani, and I. Hirota, 1987: Multiple planetary flow regimes in the Southern Hemisphere. J. Meteor Soc. Japan, 65 , 571-586, https://doi.org/10.2151/jmsj1965.65.4_571.

Yuan, X., 2004: ENSO-related impacts on Antarctic sea ice: A synthesis of phenomenon and mechanisms. Antarct. Sci., 16, 415-425, https://doi.org/10.1017/S0954102004002238.

—, and D. G. Martinson, 2001: The Antarctic dipole and its predictability. Geophys. Res. Lett., 28, 3609-3612, https:// doi.org/10.1029/2001GL012969.

— , and C. Li, 2008: Climate modes in southern high latitudes and their impacts on Antarctic sea ice. J. Geophys. Res., 113, C06S91, https://doi.org/10.1029/2006JC004067.

Yue, S., P. Pilon, and G. Cavadias, 2002: Power of the MannKendall and Spearman's rho tests for detecting monotonic trends in hydrological series. J. Hydrol., 259, 254-271, https:// doi.org/10.1016/S0022-1694(01)00594-7. 